\title{
Produção diferencial de pró-colágeno tipo I e citocinas por fibroblastos humanos de ligamento periodontal e de gengiva estimulados por lipopolissacarídeo de Porphyromonas gingivalis
}

\author{
Ana Carolina de Faria Morandini
}

Dissertação apresentada à Faculdade de Odontologia de Bauru, da Universidade de São Paulo, como parte dos requisitos necessários para obtenção do título de MESTRE em Odontologia, área de Reabilitação Oral

BAURU

2009 


\begin{tabular}{|c|c|}
\hline \multirow[t]{3}{*}{ M794p } & $\begin{array}{l}\text { Morandini, Ana Carolina de Faria } \\
\text { Produção diferencial de pró-colágeno tipo I e } \\
\text { citocinas por fibroblastos humanos de ligamento } \\
\text { periodontal e de gengiva estimulados por } \\
\text { lipopolissacarídeo de Porphyromonas gingivalis/ Ana } \\
\text { Carolina de Faria Morandini - Bauru, } 2009 \text {. } \\
\quad \text { xx, } 80 \text { p. : il. ; } 30 \mathrm{~cm} \text {. }\end{array}$ \\
\hline & $\begin{array}{l}\text { Dissertação (Mestrado) }-- \\
\text { Odontologia de Bauru. Universidade de São Paulo. }\end{array}$ \\
\hline & Orientador: Prof. Dr. Carlos Ferreira dos Santos \\
\hline
\end{tabular}

Autorizo, exclusivamente pra fins acadêmicos e científicos, a reprodução total ou parcial desta tese, por processos fotocopiadores e/ou meios eletrônicos.

Assinatura do autor:

Data:

Comitê de Ética em Pesquisa em Seres Humanos da FOBUSP: projeto de pesquisa aprovado em 29 de agosto de 2007.

Número do processo: 057/2007 



\section{DADOS CURRICULARES}

\section{Ana Carolina de Faria Morandini}

Nascimento

$2003-2006$

$2004-2006$

2007 - Atual

\#

\#

\#

\#

\#

\#
10 de dezembro de 1985

Agudos - São Paulo

Graduação em Odontologia pela Faculdade de Odontologia de Bauru da Universidade de São Paulo - FOB/USP

Bolsista do Programa de Educação Tutorial (PET) do Ministério da Educação - Secretaria de Ensino Superior (MEC - SESu)

Mestrado em Reabilitação Oral, na Faculdade de Odontologia de Bauru, Universidade de São Paulo - FOB/USP 
\#

\#

\section{DEDICATÓRIA}

\#

\#

À minha família,

Com todo o meu amor...

"Obstáculos são aquelas coisas medonhas que você vê quando tira os olhos de seu objetivo."

(Henry Ford) 


$$
\longrightarrow
$$




\section{AGRADECIMENTOS}

A DEUS, acima de tudo, de onde vem a força maior, a fé que me faz crescer como ser humano a cada dia.

Aos meus pais, José Carlos e Fátima, que me deram a oportunidade de vir ao mundo, que sempre acreditaram em mim, que me estimulam, me fortalecem, me apoiam, me ajudam nas dificuldades, me aturam com paciência nos momentos mais delicados e me mostram os erros. Agradeço por me proporcionarem os momentos mais preciosos da minha vida.

Aos meus irmãos, Paulo Henrique e José Eduardo, pelo carinho e cumplicidade, cada um à sua maneira, mas sempre presentes, apesar da distância.

Aos meus avós, tios e primos, pela força, pela torcida, pela compreensão da minha ausência em muitos momentos.

Ao meu orientador, Prof. Dr. Carlos Ferreira dos Santos, por cumprir o seu papel com tanta dedicação e brilhantismo, fundamentais para a realização deste trabalho. Obrigada pelas palavras de encorajamento, por sua inteligência e clareza. Obrigada pelo exemplo de profissionalismo, pela compreensão, por cada detalhe que me inspira a seguir este caminho. Agradeço por compreender as minhas limitações e por me fazer crescer a cada momento de aprendizado que tive durante o meu mestrado.

A Fundação de Amparo à Pesquisa do Estado de São Paulo (FAPESP), pelo financiamento deste trabalho por meio de auxílio à pesquisa (Processo FAPESP 05/60167-0). 
À Carla Renata Sipert (Angel), minha "orientadora" e amiga tão querida que teve a paciência de me ensinar tudo o que eu não sabia sobre fibroblastos, sobre a bancada de um laboratório, sobre ser pesquisadora, sobre ser humana...A minha admiração por você cresce a cada dia. Só tenho que agradecer a Deus por ter encontrado um anjo como você (agora entendo o apelido) durante o Mestrado.

Ao Prof. Dr. Sebastião Luiz Aguiar Greghi, pela orientação no primeiro ano de Mestrado, mais que isso, pelos ensinamentos clínicos que me foram passados sempre com excelência, pelo exemplo de humildade e coleguismo, por estar sempre disponível para me ajudar, pela pessoa que é e que admiro muito. Obrigada mesmo!!

Aos Professores da Disciplina de Periodontia da FOB/USP: Prof. Dr. Euloir Passanezi, Prof ${ }^{a}$. Dr ${ }^{a}$ Adriana Passanezi Sant'Ana e Prof ${ }^{a} \operatorname{Dr}^{a}$ Maria Lucia Rubo de Resende

Aos meus amigos ex-PETIANOS, que continuaram comigo de uma forma ou de outra, até como colegas de mestrado e que são como uma família. Vocês serão sempre lembrados com muito carinho. Só quero que saibam que agradeço muito por fazerem parte da minha vida, Marina Maguollo, Tiago Mergulhão (Camarão), Mariana Gigliotti, Marco Aurélio Paschoal (Krek), Carol Ortigosa, Bruna Stuchi Centurion, Thaís Maria Fernandes, Marcelo Polleti. Amo vocês.

Aos meus colegas de Pós-Graduação com os quais compartilhei momentos maravilhosos ao longo desses 2 anos: Elen Tolentino (Tubs), Bruno Aiello, Bruno Furquim, Marcus Gustavo Rodrigues, Roberta Domingues, Bruna Rahal Ferraz, Eduardo Aleixo Figueira, Pedro Coesta, Carlos Eduardo Repeke, Samuel B. Ferreira Jr., Marcela Claudino da Silva, Erivan Schnaider Ramos Jr, Thais Helena Gasparoto, Hayana Ramos Lima, Tatiana Salles, Natalino Lourenço Neto, Felipe Ramalho Ferreira e ao pessoal do programa de Reabilitação Oral. Valeu mesmo!! Agradeço também, de maneira especial, aos queridos estagiários da Periodontia: Samira, Rafael e Mônica 
Ao Thiago Dionísio, técnico do laboratório de Farmacologia, pela ajuda, pela paciência, pela amizade, pela confiança...muito obrigada! Agradeço também às amigas do laboratório de Farmacologia: Thaís, Marta, Ana Eliza, Karin, Lucimara, Adriana e Déborinha!!

À Karen, meu exemplo de vida e de competência, por me fazer amar a Dança e a Odontologia e me mostrar que é possível conciliar as duas quando amamos o que fazemos... pelo carinho de todos esses anos, amizade, companheirismo, pela confiança profissional, paciência e compreensão, principalmente nos momentos em que estive ausente dos ensaios, especialmente neste ano por entender exatamente o que acontece na minha vida e me ajudar a conciliar as coisas, sem perder o equilíbrio.

À Família da Sigma Academia de Dança de Bauru, que há 14 anos faz parte da minha vida... pela convivência maravilhosa, pela energia que temos como grupo, pela força... devo muito a vocês.

Ao Prof. Dr. Gustavo Pompermaier Garlet e à Prof ${ }^{a} \operatorname{Dr}^{a}$ Ana Paula Campanelli, pela maravilhosa colaboração neste trabalho...Obrigada.

À Faculdade de Odontologia de Bauru, Universidade de São Paulo, por meio de seu diretor, Prof. Dr. Luiz Fernando Pegoraro, e à Presidente da Comissão de Pós Graduação Prof ${ }^{a}$. Dr ${ }^{a}$. Maria Aparecida Andrade Moreira Machado, pelo apoio de sempre. Os meus sinceros agradecimentos.

Aos pacientes que colaboraram para o acontecimento deste trabalho.

Aos funcionários da FOB-USP, muito obrigada. 


$$
\longrightarrow
$$




\section{Sumário}

\begin{tabular}{lc} 
RESUMO e ABSTRACT & $\mathbf{x x}$ \\
\hline
\end{tabular}

1 Introdução e Síntese Bibliográfica $\quad 3$

2 Proposição

3.1 Coleta de tecido de ligamento periodontal e de gengiva......................................................... 19

3.2 Cultura de fibroblastos

3.3 Estimulação de fibroblastos de ligamento periodontal e de gengiva por lipopolissacarídeo de $P$. gingivalis

3.4 Avaliação da expressão de pró-colágeno tipo I, MIP-1 $\alpha$, SDF-1 e IL-6 por fibroblastos

de ligamento periodontal e de gengiva

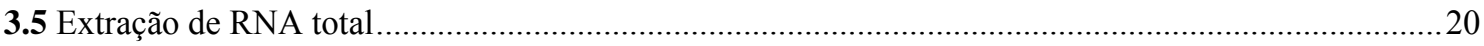

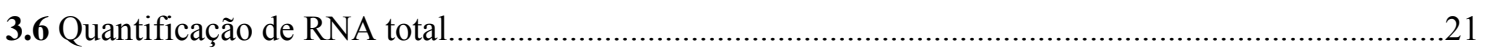

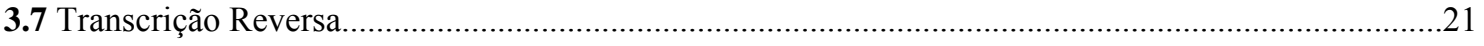

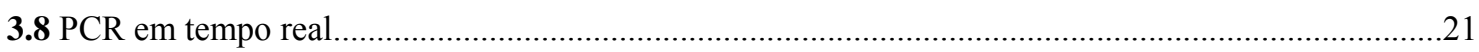

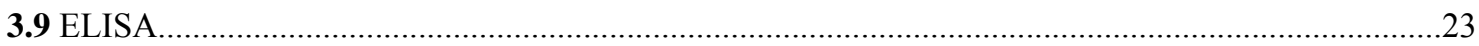

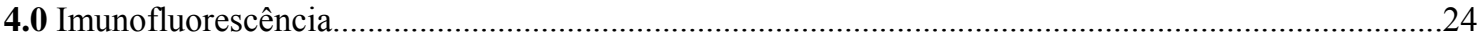

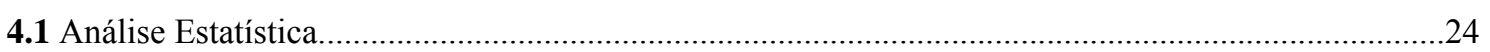

5 Resultados $\quad 29$

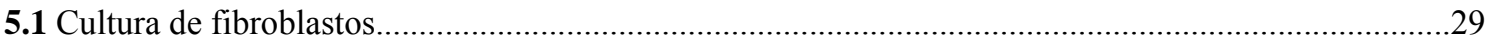

5.2 Expressão de Pró-Colágeno tipo I por PCR em tempo real e detecção desta proteína por Imunofluorescência .33

5.3 Expressão de MIP-1 $\alpha$, SDF-1 e IL-6 por fibroblastos de ligamento periodontal e de gengiva por PCR em tempo real

5.4 Produção de MIP-1 $\alpha$, SDF-1 e IL-6 por fibroblastos de ligamento periodontal e de gengiva por ELISA.

6 Discussão 


$$
\longrightarrow
$$




\section{Lista de Figuras}

\#

FIGURA 1 Cultura de fibroblastos humanos de ligamento periodontal e de $\mathbf{3 1}$ gengiva

FIGURA 2 Expressão de RNAm para pró-colágeno tipo I por fibroblastos 33 de ligamento periodontal e de gengiva estimulados por lipopolissacarídeo de Porphyromonas gingivalis.

FIGURA 3 Produção de pró-colágeno tipo I em fibroblastos de ligamento periodontal por Imunofluorescência.

FIGURA 4 Expressão de RNAm para MIP-1 $\alpha$ por fibroblastos de ligamento periodontal e de gengiva estimulados por lipopolissacarídeo de Porphyromonas gingivalis.

FIGURA 5 Expressão de RNAm para SDF-1 por fibroblastos de ligamento periodontal e de gengiva estimulados por lipopolissacarídeo de Porphyromonas gingivalis.

FIGURA 6 Expressão de RNAm para IL-6 por fibroblastos de ligamento periodontal e de gengiva estimulados por lipopolissacarídeo de Porphyromonas gingivalis

FIGURA 7 Produção de MIP-1 $\alpha$ por fibroblastos de ligamento periodontal e de gengiva estimulados por lipopolissacarídeo de Porphyromonas gingivalis

FIGURA 8 Produção de SDF-1 por de ligamento periodontal e de gengiva estimulados por lipopolissacarídeo de Porphyromonas gingivalis

FIGURA 9 Produção de IL-6 de ligamento periodontal e de gengiva estimulados por lipopolissacarídeo de Porphyromonas gingivalis. 


$$
\longrightarrow
$$




\section{Lista de Abreviaturas e Símbolos}

$\circ=$ graus

$\%=$ por cento

et al $=$ e colaboradores

$\mathrm{h}=$ hora

RNA $=$ Ácido ribonucléico

RNAm $=$ RNA mensageiro

$\mathrm{pb}=$ pares de base

mi RNA $=$ microRNA

LPS $=$ Lipopolissacarídeo

TGF $=$ Transforming Growth Factor - Fator de crescimento transformador

$\mathrm{IL}=$ Interleucina

IL-6 = Interleucina-6

$\mathrm{GRO}=$ Growth-related Oncogene - Oncogene relacionado ao crescimento

$\mathrm{SDF}=$ Stromal Cell-Derived Factor - Fator celular derivado de estroma

$\mathrm{MCP}=$ Monocyte Chemotactic Protein - Proteína quimiotática para monócito

MIP = Macrophage Inflammatory Protein - Proteína inflamatória para macrófago

TNF $=$ Tumor Necrosis Factor - Fator de necrose tumoral

IP = Interferon-gama-inducible Protein - Proteína indutora de Interferon-gama

$\mathrm{NK}=$ Natural Killer - Células do sistema imune denominadas de "Exterminadoras Naturais"

$\mathrm{IFN}=$ Interferon

$\mathrm{CD}=$ Cluster of differentiation - Agrupamento de diferenciação

TLR $=$ Toll-like Receptor - Receptor do tipo Toll

MyD = Myeloid Differentiation - Diferenciação mielóide

NOD = Nucleotide-binding Oligomerization Domain - Domínio de oligomerização ligado a nucleotídeo

A.a = Aggregatibacter Actinomycetemcomitans

RT-PCR $=$ Reverse Transcriptase - Polymerase chain reaction - Transcriptase reversa seguida de reação em cadeia da polimerase

DMEM = Dulbecco's Modified Eagle's Medium - Meio de Eagle modificado por Dulbecco

BHI = Brain Heart Infusion - Infusão de cérebro e coração

PBS = Phosphate Buffered Saline - Solução salina tamponada por fosfato

PBS-T = Phosphate Buffered Saline in Tween 20 - Solução salina tamponada por fosfato em Tween 20 a $0,05 \%$

ELISA = Enzyme Linked Immuno Sorbent Assay = Ensaio imuno-enzimático

FOB/USP = Faculdade de Odontologia de Bauru / Universidade de São Paulo 


$$
\longrightarrow
$$




\section{RESUMO}

O ligamento periodontal e o tecido gengival são formados por tecido conjuntivo frouxo, sendo constituídos por diversas células, dentre as quais os fibroblastos são as mais numerosas. Ao serem submetidas a agressões diversas, estas células respondem com a liberação de substâncias, tais como citocinas e quimiocinas, que participam de maneira ativa no processo inflamatório, e com a produção de componentes da matriz extracelular fundamentais para o reparo, como por exemplo, o colágeno. Assim sendo, este trabalho teve como objetivo: Avaliar e comparar a expressão e a produção de pró-colágeno tipo I, IL-6, MIP-1 $\alpha$ e SDF-1 por fibroblastos humanos, cultivados de ligamento periodontal e de tecido gengival, estimulados por lipopolissacarídeo (LPS) de Porphyromonas gingivalis. Foram coletados ligamentos periodontais de terceiros molares não irrompidos e biópsias de gengiva de um mesmo indivíduo $(n=3)$. Estes tecidos foram picotados e mantidos em meio de cultura adequado para fibroblastos, que foram utilizados na quarta passagem. Após adesão dos fibroblastos a placas de 24 poços, o meio de cultura contendo 0,1 - $10 \mu \mathrm{g} / \mathrm{mL}$ de LPS de $P$. gingivalis foi adicionado às placas em duplicata. $O$ sobrenadante e as células foram coletados após 1, 6 e 24 horas e analisados por ELISA e PCR em tempo real, respectivamente. A análise estatística foi realizada por meio do programa GraphPad Prism, aplicando-se o teste ANOVA a 1 critério com nível de significância de 5\%. A expressão de pró-colágeno tipo I mostrou-se ligeiramente diferente entre fibroblastos de ligamento periodontal e de gengiva. A produção de IL-6, MIP-1 $\alpha$ e SDF-1 foi significativamente maior em fibroblastos gengivais. A citocina IL-6 foi produzida de maneira tempo-dependente com LPS de $P$ gingivalis, principalmente por fibroblastos gengivais. Para MIP-1 $\alpha$, os fibroblastos gengivais mostraram maior produção com a menor concentração de estímulo $(0,1 \mu \mathrm{g} / \mathrm{ml})$. Para SDF-1, foi detectada produção constitutiva que foi inibida com o aumento da concentração de LPS ao longo do tempo nestas mesmas células. Já para fibroblastos de ligamento periodontal, não foi observado um padrão homogêneo e linear, apesar de a produção basal de SDF-1 também existir, porém em níveis bem mais discretos, como aquele observado para a produção de MIP-1 $\alpha$. A capacidade dos fibroblastos modificarem o padrão de produção dessas citocinas frente ao estímulo com LPS de $P$. gingivalis reforça a importância dessas células no contexto da resposta imune do indivíduo frente à doença periodontal.

Palavras-chave: Fibroblastos. Citocinas. Periodontite. 
<smiles>CCCC</smiles> 
Differential production of pro-collagen type I and cytokines by cultured human periodontal ligament and gingival fibroblasts challenged with lipopolyssacharide from Porphyromonas gingivalis

The fibroblast is considered an important cell in periodontitis because it is the predominant cell type in the periodontal connective tissue. When challenged by different agents, fibroblasts respond through the release of substances, such as cytokines and chemokines that participate in an active way in the inflammatory process as well as the production of basic components of the extracellular matrix for repair, like collagen. The aim of this study was to: to evaluate and to compare the expression and production of type I pro-collagen, IL-6, MIP-1 $\alpha$ and SDF-1 by cultured human periodontal ligament and gingival fibroblasts challenged with lipopolyssacharide from Porphyromonas gingivalis. Human periodontal ligament and gingival fibroblasts were cultured from biopsies of the same donor and were used on the fourth passage. After confluence in 24-well plates, the culture medium alone (control) or with $0,1-10 \mathrm{ug} / \mathrm{mL}$ of LPS from P. gingivalis were added and after 1, 6 and 24 hours, the supernatant and the cells were collected and analysed by ELISA and Real time PCR, respectively. Data were analysed by GraphPad Prism Program (1 way - ANOVA test) and a significance level of $5 \%$ was adopted. Pro-collagen type I expression by Real Time PCR differ between periodontal ligament and gingival fibroblasts. In vitro experiments revealed that IL-6, MIP$1 \alpha$ and SDF-1 production were significantly greater in gingival fibroblasts when compared to periodontal ligament. In addition, IL-6 was upregulated in a time-dependent manner, mainly by the gingival fibroblasts. On one hand, MIP-1 $\alpha$ was stimulated with a low concentration $(0,1$ ugml) of LPS by gingival fibroblasts. On the other hand, SDF-1 was constitutively secreted by the same cells but its production was inhibited when challenged by a higher concentration of LPS from $P$ gingivalis. In general, periodontal ligament fibroblasts did not show a pattern of production of these cytokines under the challenge with LPS, despite of the basal production of SDF-1 in lower levels than gingival cells and the low production of MIP-1 $\alpha$ over time. The differential ability of the gingival and periodontal ligament fibroblasts to secrete these cytokines emphasizes their crucial role in the inflammatory microenvironment and in the host immune response to periodontal disease.

Keywords: Fibroblasts. Cytokines. Periodontitis. 
<smiles>CCCC</smiles> 


\section{Introdução e Sintese Bibliográfica}

\#

\subsection{O Ligamento Periodontal}

O ligamento periodontal é constituído por um complexo vascular e por tecido conjuntivo intensamente celularizado ao redor da raiz do dente, sendo conectado à parede mais interna do osso alveolar (MCCULLOCH; LEKIC; MCKEE, 2000). Ele é contínuo com o tecido conjuntivo gengival e se comunica com os espaços medulares por meio de canais vasculares no osso. Embora a média de espaço do ligamento periodontal seja em torno de 0,2 $\mathrm{mm}$, variações consideráveis acontecem. O espaço periodontal é diminuído em dentes não irrompidos e que não estão em função, e se encontra aumentado em dentes submetidos a uma hiperfunção (FIORELLINI; KIM; ISHIKAWA, 2006). Os elementos mais importantes do ligamento periodontal são as fibras colágenas principais, que, em suas porções terminais, estão inseridas de um lado no cemento e de outro no osso alveolar recebendo o nome de fibras de Sharpey. Essas fibras estão associadas com proteínas não colágenas abundantes como a osteopontina e sialoproteína óssea tipicamente encontradas no tecido ósseo e também no cemento dentário (NEWMAN et al., 2006).

As fibras principais do ligamento periodontal estão arranjadas em 6 grupos que se desenvolvem sequencialmente na raiz em desenvolvimento: as transseptais, da crista alveolar, horizontais, oblíquas, apicais e interradiculares (FIORELLINI; KIM; ISHIKAWA, 2006). As fibras principais são remodeladas pelas células do ligamento periodontal para se adaptarem às necessidades fisiológicas (TEN CATE; DEPORTER, 1975; YAMAMOTO; WAKITA, 1982) e em resposta aos diferentes estímulos. Foram identificados quatro tipos celulares que compõem o ligamento periodontal: células do tecido conjuntivo, células de restos epiteliais, células do sistema imune e células associadas com elementos neurovasculares (BERKOVITZ; SHORE, 1982).

As células do tecido conjuntivo incluem fibroblastos, cementoblastos e osteoblastos. Fibroblastos são o tipo celular mais comum no tecido do ligamento periodontal e aparecem como tipos celulares ovóides ou alongados, em formato fusiforme e com longas projeções citoplasmáticas, orientados ao longo das fibras principais. Essas células sintetizam colágeno e possuem a capacidade de fagocitar fibras colágenas "velhas" e de degradá-las (TEN CATE; 
DEPORTER, 1975) por hidrólise enzimática. Então, a renovação do colágeno parece ser regulado pelos fibroblastos em um processo de degradação intracelular (BEERTSEN; MCCULLOCH; SODEK, 1997). Subpopulações de fibroblastos fenotipicamente distintos e funcionalmente diferentes povoam o ligamento periodontal. Podem exercer diferentes funções como a secreção de diferentes tipos de colágeno e a produção de colagenase. Os restos epiteliais de Malassez, considerados remanescentes da bainha epitelial de Hertwig, que se desintegra durante o desenvolvimento radicular, estão distribuídos próximos ao cemento ao longo do tecido do ligamento periodontal, sendo mais numerosos na área apical e cervical (REEVE; WENTZ, 1962). As células de defesa presentes no ligamento periodontal incluem neutrófilos, linfócitos, macrófagos e eosinófilos. Essas células, bem como as associadas com elementos neurovasculares, são similares às que estão presentes em outros tecidos conjuntivos do organismo. O ligamento também contém uma larga porção de matriz extracelular que consiste basicamente de glicosaminoglicanas e glicoproteínas, preenchendo os espaços entre as fibras e as células. As funções do ligamento periodontal podem ser categorizadas em físicas, como a transmissão das forças oclusais para o osso, função formativa e de remodelação, que ocorre fisiologicamente com o movimento dentário e também em resposta às injúrias, função nutricional e ainda sensorial (FIORELLINI; KIM; ISHIKAWA, 2006).

\subsection{A Gengiva}

A gengiva é microscopicamente composta por epitélio escamoso estratificado predominantemente celular recobrindo um tecido conjuntivo frouxo menos celular e composto primariamente por fibras colágenas e matriz extracelular. O principal tipo celular do epitélio gengival, assim como outros epitélios estratificados, é o queratinócito. A principal função do epitélio gengival, que está dividido entre epitélio do sulco e juncional, é proteger as estruturas localizadas mais profundamente a ele, enquanto permite um intercâmbio seletivo com o ambiente bucal. Isso é conseguido pela proliferação e diferenciação de queratinócitos. O epitélio juncional, em particular, exibe várias características estruturais e funcionais que contribuem para a prevenção da colonização da superfície radicular subgengival por bactérias patogênicas (NEWMAN et al., 2006). 
Já o tecido conjuntivo gengival tem como principais componentes as fibras colágenas (aproximadamente $60 \%$ do volume), fibroblastos, vasos, nervos, e matriz extracelular. As fibras colágenas consistem de Colágeno tipo I e estão arranjadas em 3 grupos: gengivodentais, circulares e transseptais (ROMANOS; BERNIMOULIN, 1990).

O elemento celular preponderante no tecido conjuntivo gengival é o fibroblasto, sendo que muitos estão localizados entre as fibras exercendo um papel fundamental no desenvolvimento, manutenção e reparo do tecido conjuntivo gengival. Assim como no ligamento periodontal ou em um tecido conjuntivo em qualquer outro lugar do organismo, o fibroblasto é uma célula que tem como papel principal sintetizar o colágeno e fibras elásticas, assim como glicoproteínas e glicosaminoglicanas da matriz extracelular (NEWMAN et al., 2006).

\subsection{Os estímulos agressores e a resposta dos fibroblastos}

A resposta dos fibroblastos frente a estímulos microbianos tem sido estudada em situações diversas. Como exemplo de desafios escolhidos, podem ser citados: lipopolissarídeos (LPS), antígeno proveniente da parede celular de bactérias gram-negativas (TAMURA et al., 1992; YAMAJl et al., 1995; WANG et al., 1998; WANG et al., 1999; WANG et al., 2000; GUTIERREZ-VENEGAS et al., 2005), ácido lipoteicóico (LTA), proveniente da parede celular de bactérias gram-positivas (TELLES et al., 2003), extrato sonicado de bactérias (YAMASAKI et al., 1998), sobrenadante de bactérias bucais (LETZELTER et al., 1998), bactérias íntegras inativadas (SUGIYAMA et al., 2000; HOSOKAWA et al., 2005) e peptidioglicana (HATAKEYAMA et al., 2003). A importância de microrganismos na etiopatogenia da doença periodontal já vem sendo amplamente descrita na literatura (QUIRYNEN et al., 2006).

O conceito atual da etiologia da periodontite considera que três grupos de fatores determinam se a periodontite ativa poderá acometer o indivíduo: a suscetibilidade do hospedeiro, a presença de espécies patogênicas e a ausência ou proporção pequena de "bactérias benéficas". As manifestações clínicas da destruição periodontal resultam, então, de uma complexa relação entre os agentes etiológicos, como patógenos específicos da placa dentobacteriana, e os tecidos hospedeiros. Quando o equilíbrio entre a carga bacteriana e a resposta do hospedeiro é rompido, a destruição periodontal pode ocorrer (QUIRYNEN et al., 
2006). A suscetibilidade do indivíduo é parcialmente hereditária, mas pode ser influenciada por fatores ambientais e de comportamento, como o tabagismo, o estresse e diabetes.

Vários estudos demonstraram uma ligação significativa entre marcadores genéticos específicos (associados com o aumento da produção de interleucina-1) e suscetibilidade periodontal (GENCO; LOE, 1993; ALBANDAR; RAMS, 2002). A não ser pelas dificuldades inerentes de caracterização da microbiologia da doença periodontal, um pequeno grupo de patógenos é reconhecido por sua forte associação com a doença. São eles Aggregactibacter actinomycetencomitans, Tannerela forsythia e Porphyromonas gingivalis como patógenos principais, pois são fortemente associados com a situação de periodontite, progressão da doença e insucesso na terapia. Outras bactérias, porém em nível de evidência mais moderado para etiologia, podem ser destacadas : Prevotella intermedia, Prevotella nigrescens, Campylobacter rectus, Peptostreptococcus micros, Fusobacterium nucleatum, Eubacterium nodatum e vários espiroquetas (SLOTS; RAMS, 1991; SOCRANSKY; HAFFAJEE, 1992). P.gingivalis é um dos bacteróides com pigmentação negra isolado principalmente no sulco gengival, sendo a placa dentobacteriana seu nicho ecológico (VAN WINKELHOFF; VAN STEENBERGEN; DE GRAAFF, 1988). Tem sido associada a quadros patológicos sintomáticos como abscessos tanto de origem endodôntica como periodontal, pericoronarite e complicações pós-exodontia (VAN WINKELHOFF; VAN STEENBERGEN; DE GRAAFF, 1988). Este microrganismo tem sido descrito como um dos mais patogênicos encontrados na cavidade bucal (MAYRAND; HOLT, 1988). Essa virulência é resultado das endotoxinas presentes nessas bactérias: fímbrias, cápsulas, hemaglutinina e, em especial, lipopolissacarídeos (LPS) (GOMES et al., 2005).

O LPS é um componente da membrana externa de bactérias gram-negativas capaz de exibir intensa imuno-estimulação e atividade inflamatória (RIETSCHEL et al., 1996). O LPS é capaz de causar ativação celular imediata e liberação de citocinas pró-inflamatórias por macrófagos (RIETSCHEL et al., 1996). Várias moléculas podem estar envolvidas na migração e recrutamento de leucócitos específicos. Recentemente, tem sido discutido que em resposta a estímulos variados, os fibroblastos gengivais, além de produzirem colágeno, têmse mostrado capazes de secretar também vários tipos de citocinas como o fazem células de defesa (TAKASHIBA et al., 1992; TAMURA et al., 1992; KURU et al., 1998; LETZELTER et al., 1998; SUGAWARA et al., 1998; KENT; RAHEMTULLA; MICHALEK, 1999; WANG et al., 1999; TABETA et al., 2000; WANG et al., 2000; TAKASHIBA; NARUISHI; MURAYAMA, 2003; 
GUTIERREZ-VENEGAS et al., 2005; HOSOKAWA et al., 2005; ALMASRI et al., 2007; MINAMI et al., 2007; ARA et al., 2008), e da mesma forma os fibroblastos do ligamento periodontal (YAMAJl et al., 1995; HOSOKAWA et al., 2005; PATIL; ROSSA; KIRKWOOD, 2006; YAMAMOTO et al., 2006; VERARDI et al., 2007).

Citocinas são proteínas secretadas por células de imunidade tanto inata como adaptativa que atuam como mediadores destas mesmas células. As citocinas são produzidas em resposta a diferentes estímulos, dentre eles microrganismos, como no caso da resposta à infecção do sulco gengival por bactérias Gram-negativas, sendo que diferentes citocinas estimulam diversas respostas em células constituintes da imunidade e inflamação. Dentre as citocinas, destaca-se uma grande família de homólogos estruturais que estimulam o deslocamento de leucócitos e regulam sua migração do sangue aos tecidos. A estas citocinas, deu-se o nome de quimiocinas (citocina quimiotática). Elas são produzidas por várias células em resposta a estímulos inflamatórios recrutando, assim, leucócitos ao local da inflamação(ABBAS; LICHTMAN, 2007). As quimiocinas são todas polipeptídeos entre 8 e 14 kDa e são classificadas em subfamílias com base no número e posição dos resíduos de cisteína N-terminal. As duas maiores subfamílias são a CC (quando resíduos de cisteína estão adjacentes) e a CXC (quando os resíduos são separados por um aminoácido). Um número menor de quimiocinas é classificado como $C$ (apenas um resíduo de cisteína) ou CX3C (três aminoácidos separando os resíduos) (ZLOTNIK; YOSHIE, 2000). As quimiocinas dos grupos CC e CXC são produzidas por leucócitos, células endoteliais, células epiteliais e também por fibroblastos. A expressão de quimiocinas pode ser induzida por complexos imunes, mediadores pró-inflamatórios, incluindo IL-1, fator de necrose tumoral (TNF), interferon- $\gamma$ (IFN- $\gamma$ ) e produtos microbianos como LPS (JIANG; GRAVES, 1999; LUKACS, 2001; JOHN; LUKACS, 2003). Essa liberação constitui um importante mecanismo de defesa, pois recruta leucócitos para a região onde ocorre a infecção(ABBAS; LICHTMAN, 2007).

O tipo de infiltrado que caracteriza uma doença específica é controlado em parte por grupos distintos de quimiocinas que atraem especificamente os diferentes tipos celulares de leucócitos (HERLAAR; BROWN, 1999). A população celular do infiltrado inflamatório também se altera durante a progressão da doença e o tipo de quimiocina é um importante determinante dos tipos celulares presentes nesse infiltrado (LUKACS, 2001). Quimiocinas da subfamília CXC, como a IL-8, oncongene relacionado com o crescimento (GRO) e fator estroma derivado de célula (SDF), são potentes quimiotáticos e ativadores de neutrófilos. Já 
os componentes da subfamília CC, como a proteína quimiotática para monócito (MCP) e a proteína inflamatória para macrófago (MIP), agem sobre células mononucleares em vários níveis de especificidade (SCHALL et al., 1993; OGURA et al., 2005). Por outro lado, os

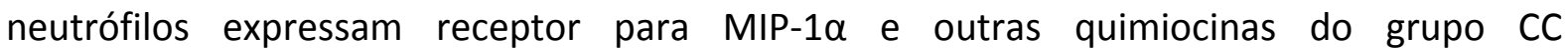
especialmente se estimulados por citocinas presentes no processo inflamatório (BONECCHI et al., 1999).

\subsection{0 papel da citocina IL-6, e das quimiocinas MIP-1 $\alpha$ e SDF-1}

A Interleucina-6 (IL-6) é uma citocina amplamente estudada como resultado a estímulos variados. Sua produção por fibroblastos de ligamento periodontal humano já foi demonstrada frente ao desafio por LPS (YAMAJI et al., 1995). Com este mesmo antígeno, a mesma citocina foi produzida por fibroblastos de gengiva humana (WANG et al., 1998; WANG et al., 1999), apesar de os mesmos autores enfatizarem a inibição desta produção pelo tratamento conjunto com IL-10 (WANG et al., 1999) e com anticorpo anti-CD-14 (WANG et al., 1998). IL-6 é conhecida por ser um dos maiores mediadores na regulação da resposta imune frente à inflamação(NEWMAN et al., 2006). Quando investigada a regulação da produção de IL-6 em fibroblastos gengivais e ligamentares humanos, observou-se uma estimulação tempo/concentração - dependente por citocinas pró-inflamatórias incluindo IL$1 \alpha / \beta$ e TNF- $\alpha$, sendo esta produção diferencialmente modulada por $\mathrm{PGE}_{2}$ endógena $\mathrm{e}$ citocinas provenientes de células T como IFN- $\gamma$ e IL-4 (OKADA et al., 1997). A exposição de células gengivais murinas ao LPS de $P$. gingivalis, mas não ao LPS de E.coli, resultou na liberação de citocinas pró-inflamatórias como TNF- $\alpha$ e IL-6, e induziu a expressão gênica de outras citocinas, como CCL25 e CCL2 (EKHLASSI et al., 2008), o que levaria a um influxo de células polimorfonucleares e mononucleares até o sítio da inflamação. A IL-6 é também um dos fatores produzidos por células osteoclásticas, dentre outros como MIP-1 $\alpha$ e TNF- $\alpha$, que parecem ser importantes na regulação da formação de clastos em situação normal ou patológica (ROODMAN, 2006). Quando incubados com LPS de P. gingivalis, fibroblastos gengivais foram capazes de liberar IL-6 e IL-10 (WANG et al., 1999) e ainda de induzir a expressão de mRNA para IL-8 (TAMURA et al., 1992). No entanto, este mesmo estímulo levou à redução da produção de SDF-1 $\alpha / \beta$ (CXCL12) por fibroblastos gengivais humanos, o 
que pode afetar a homeostasia do tecido periodontal normal, uma vez que estas células produzem esta quimiocina constitutivamente (HOSOKAWA et al., 2005).

A produção constitutiva de SDF-1 foi primeiramente constatada em células do estroma de medula óssea (AIUTI et al., 1997). No entanto, a produção dessa quimiocina também já foi demonstrada por fibroblastos sinoviais da articulação têmporomandibular humana (OGURA et al., 2005) e por fibroblastos de gengiva humana (FEDYK et al., 2001; HOSOKAWA et al., 2005). SDF-1 é quimiotática para leucócitos incluindo neutrófilos, monócitos, linfócitos T e B e células progenitoras hematopoiéticas(BLEUL et al., 1996; AIUTI et al., 1997; CHAN; HYDUK; CYBULSKY, 2001). Ela parece também contribuir para o retorno de neutrófilos para a medula, uma vez que estas células se mostram ainda mais responsivas a esta quimiocina quando idosas (MARTIN et al., 2003). Células dendríticas respondem a um amplo espectro de quimiocinas incluindo MIP-1 $\alpha$ e SDF-1. No entanto, com a maturação, essas células perdem a responsividade para muitas quimiocinas, mas não para SDF-1 (DIEU et al., 1998). Existem alguns indícios na literatura de que pode haver diminuição da produção de SDF-1 durante o processo inflamatório (FEDYK et al., 2001; HOSOKAWA et al., 2005). Por outro lado, indivíduos portadores de doença periodontal tiveram níveis maiores de SDF-1 $\alpha$ no fluido crevicular gengival quando comparados com indivíduos saudáveis. A migração de neutrófilos também se mostrou aumentada na presença da quimiocina SDF-1 $\alpha$, sugerindo que a mesma possa ser um importante biomarcador do fluido gengival para identificação da progressão da doença periodontal (HAVENS et al., 2008).

Células diretamente envolvidas na resposta imune como macrófagos, linfócitos T e B, neutrófilos, células dendríticas, mastócitos e células NK ("Natural Killers") são capazes de produzir grande quantidade de MIP-1 $\alpha$. Plaquetas, osteoblastos, células epiteliais e fibroblastos, dentre outras, também o fazem, porém em quantidade menor (KASAMA et al., 1993; SCHALL et al., 1993; YANG et al., 1997). A produção de MIP-1 $\alpha$ pode ser induzida por diversos agentes pró-inflamatórios, LPS, substância P, infecções virais, TNF- $\alpha$, IFN- $\gamma$ e IL$1 \alpha / \beta$.

Outras citocinas, como IL-4 e IL-10, podem levar à diminuição da produção de MIP$1 \alpha$ (MAURER; VON STEBUT, 2004). Esta quimiocina participa tanto da fase aguda como crônica da inflamação por meio do recrutamento de células inflamatórias ao local de dano ou infecção. MIP-1 $\alpha$ exerce quimiotaxia para monócitos (migração transendotelial), linfócitos B, neutrófilos ativados (BONECCHI et al., 1999) e eosinófilos (MAURER; VON 
STEBUT, 2004). É capaz de atrair ainda linfócitos CD4+ e CD8+ tanto sob fenótipo de memória como naive (SCHALL et al., 1993). As evidências mostradas na literatura constatam que MIP-1 $\alpha$ desempenha um papel muito importante na indução e modulação da resposta imune inflamatória (MAURER; VON STEBUT, 2004). Células positivas a certos receptores de quimiocinas estão presentes em níveis muito baixos em tecidos periodontais não inflamados e saudáveis, mas são encontrados em níveis aumentados em tecidos periodontais inflamados (KABASHIMA et al., 2002; GARLET et al., 2003). Em um periodonto inflamado, células positivas para MIP-1 $1 \alpha$ são mais abundantes do que para outras quimiocinas (GEMMELL; MARSHALL; SEYMOUR, 1997).

LPS de $P$ gingivalis e A actinomicetemcomitans induz aumento dos níveis de MIP-1 $\alpha$ em células mononucleares (JIANG; GRAVES, 1999), e ainda é capaz de ativá-las, em cultura de células de medula óssea, para formar células osteoclásticas, resultando em reabsorção óssea (HAN et al., 2001). Essa relação do MIP-1 $\alpha$ com a formação e ativação osteoclástica sugere um papel para essa quimiocina mesmo nos estágios mais precoces da periodontite. Níveis elevados de MIP-1 $\alpha / C C L 3$ são relatados em várias doenças caracterizadas pela perda óssea induzida pela inflamação (CHOI et al., 2000). A produção desregulada de MIP-1 $\alpha$ nos tecidos periodontais parece ser etiologicamente importante na destruição periodontal observada na Síndrome de Papillon-Lefévre (RYU et al., 2005). Certas quimiocinas, incluindo MIP-1 $\alpha$ e proteína quimioatraente para monócito 1 (MCP-1) são expressas no epitélio de tecido gengival inflamado. E ainda, a expressão de MIP-1 $\alpha$ não é diminuída com o aumento da inflamação, onde a expressão de outras quimiocinas parece diminuir (GEMMELL; MARSHALL; SEYMOUR, 1997). A habilidade desses tecidos em produzir MIP-1 $\alpha$ pode ser importante para o início e progressão da doença periodontal. A expressão de MIP-1 $\alpha$ também implicou em formação e ativação osteoclástica (CHOI et al., 2000; HAN et al., 2001), sugerindo um possível papel na destruição óssea associada com a periodontite.

Não há relatos na literatura que avaliem o comportamento de fibroblastos provenientes de ligamento periodontal comparados aos provenientes de tecido gengival do mesmo doador com relação à produção da citocina IL-6 em comparação com as quimiocinas SDF-1 e MIP-1 $\alpha$. Também não há relatos quanto à expressão de uma proteína como o prócolágeno tipo I pelas mesmas células. Tendo em vista que em processos inflamatórios, de maneira geral, as quimiocinas exercem papel fundamental no recrutamento de células de defesa, torna-se também de interesse significativo o estudo da secreção delas por células do 
tecido gengival e do ligamento periodontal - em especial os fibroblastos, por serem os mais numerosos - mediante agressão por antígenos provenientes de microrganismos envolvidos com infecções periodontais, como o LPS de $P$. gingivalis. Somando-se isso à capacidade dos fibroblastos do ligamento periodontal liberarem colágeno quando envolvidos em um processo inflamatório, o estudo desta proteína juntamente com a possibilidade de recrutamento de células de defesa (expressão de citocinas e de quimiocinas) torna verdadeiramente necessário o conhecimento detalhado destes eventos, uma vez que os fenômenos da inflamação não ocorrem da mesma maneira em todos os sítios preenchidos por tecido conjuntivo (RAVANTI et al., 1999; MARTINEZ; ARAUJO, 2004). 
<smiles>CCCC</smiles> 


\section{Proposição}

Justificativa: devido à importância dos fenômenos presentes na etiopatogenia da doença periodontal, existe a necessidade de conhecê-los em detalhes, uma vez que a inflamação não ocorre por igual em todos os tecidos conjuntivos do organismo. Pela predominância numérica dos fibroblastos no tecido gengival e no ligamento periodontal e pelos recentes relatos acerca da capacidade destas células reagirem a estímulos agressivos por meio da liberação de diversas citocinas, dentre elas quimiocinas que desempenham importante função na formação do infiltrado inflamatório, o presente trabalho teve como objetivo:

Avaliar e comparar a expressão e a produção de pró-colágeno tipo I, IL-6, MIP-1 $\alpha$ e SDF-1 por fibroblastos humanos cultivados de ligamento periodontal e de gengiva após estímulo por LPS de $P$. gingivalis. 
\#<smiles>CCCC</smiles> 


\section{Material e Métodos}

\subsection{Coleta de Ligamento Periodontal e de Tecido Gengival}

Os tecidos de ligamento periodontal e gengival provenientes de 3 pacientes livres de doenças sistêmicas foram obtidos no Laboratório de Fisiologia e Farmacologia Clínica da FOB/USP. O tecido do ligamento periodontal foi obtido do terço médio das raízes de terceiros molares hígidos imediatamente após a extração. Concomitantemente, biópsias de tecido gengival (gengiva marginal saudável) foram obtidas desses mesmos doadores. A doação dos dentes e a autorização para a biópsia gengival foram formalizadas pelos pacientes em documento específico devidamente aprovado pelo Comitê de Ética em Pesquisa da FOB/USP (057/2007). Com uma cureta periodontal, a superfície externa do cemento radicular foi cuidadosamente raspada, removendo-se assim o tecido do ligamento periodontal. Os fragmentos de gengiva do mesmo paciente foram armazenados imediatamente em meio para cultura de células - Dulbecco's modified Eaglés medium (DMEM) (Gibco, Invitrogen Corporation, Califórnia, EUA). Os tecidos coletados foram picotados para o crescimento dos fibroblastos e imersos separadamente (ligamento e gengiva) em meio de cultura acondicionado numa placa de Petri de 100x10 mm (diâmetro x altura) e mantido a $37^{\circ} \mathrm{C}$.

\subsection{Cultura de Fibroblastos}

Os tecidos provenientes de gengiva e de ligamento periodontal foram picotados com lâmina de bisturi $\mathrm{n}^{0} 15 C$ ( $B D$, São Paulo, Brasil) permanecendo imersos em meio de cultura DMEM suplementado com soro bovino fetal 10\% (Invitrogen, Califórnia, EUA), penicilina 100 $\mu \mathrm{g} / \mathrm{mL}$, estreptomicina $100 \mu \mathrm{g} / \mathrm{mL}$ e anfotericina B 0,5 mg/mL (Invitrogen, Califórnia, EUA). Os fragmentos foram centrifugados, armazenados em novo meio de cultura e mantidos na incubadora a $37^{\circ} \mathrm{C}$ e a $5 \% \mathrm{CO}_{2}$. As culturas foram mantidas até os fibroblastos alcançarem confluência com troca de meio a cada 2-3 dias. Após confluência, os fibroblastos foram tripsinizados e utilizados na 4a $^{\mathrm{a}}$ passagem conforme trabalho realizado anteriormente pelo nosso grupo (SIPERT, 2007). 


\subsection{Estimulação dos Fibroblastos de ligamento periodontal e de gengiva por LPS de Porphyromonas gingivalis}

As células foram distribuídas em placas de 24 poços na concentração de $5 \times 10^{4}$ células por poço e mantidas em incubadora a $37^{\circ} \mathrm{C}$ com $5 \%$ de $\mathrm{CO}_{2}$ por 16 horas para propiciar a adesão. O meio de cultura contendo $0,1,1$ e $10 \mu \mathrm{g} / \mathrm{mL}$ de LPS de $P$. gingivalis (tlrl - Pg LPS, Invivogen, San Diego, Califórnia) foi adicionado às placas em duplicata, conforme protocolos já descritos na literatura (SUGIYAMA et al., 2000). Para estabelecer curva tempo/resposta, foram empregados os tempos experimentais de 1, 6 e 24 horas.

\subsection{Avaliação da expressão de pró-colágeno tipo I, MIP-1 $\alpha$, SDF-1 e IL-6 por fibroblastos de ligamento periodontal e de gengiva}

Após o estímulo feito por LPS de $P$. gingivalis, a expressão de mRNA de pró-colágeno tipo I, MIP-1 $\alpha$, SDF-1 $\alpha$ e IL-6 foi avaliada por transcrição reversa (RT) seguida de reação em cadeia da polimerase (PCR) em tempo real. Adicionalmente, a produção das citocinas foi analisada por ensaio imunoenzimático (ELISA). Por fim, análise por meio de imunofluorescência foi realizada para detecção de pró-colágeno tipo I nas células de ligamento periodontal.

\subsection{Extração de RNA total}

RNA total foi extraído a partir de $1 \times 10^{5}$ células utilizando o reagente TRIZOL (Invitrogen, Califórnia, EUA). A extração de RNA total foi feita pelo método guanidinoisotiocianato-fenol-clorofórmio conforme descrito na literatura e reproduzido por nosso grupo(OLIVEIRA et al., 2008; RODINI et al., 2008; SANTOS et al., 2009). Após homogenização, as amostras foram incubadas por $5 \mathrm{~min}$ a $15^{\circ} \mathrm{C}$ e então foi adicionado um volume de $30 \%$ de clorofórmio. Os tubos foram vigorosamente agitados e deixados em repouso a $15^{\circ} \mathrm{C}$ por $5 \mathrm{~min}$, sendo em seguida centrifugados a $13.000 \mathrm{~g}$ por $15 \min$ a $4^{\circ} \mathrm{C}$. A camada superior (fase aquosa) foi recuperada em alíquotas de $400 \mu \mathrm{L}$ que foram colocadas em tubos de microcentrífuga de $1,5 \mathrm{~mL}$ contendo $1000 \mu \mathrm{L}$ de isopropanol. Os tubos foram agitados vigorosamente e deixados em repouso à temperatura ambiente por $10 \mathrm{~min}$. Após 
incubação por 16 horas a $-20^{\circ} \mathrm{C}$, foi realizada nova centrifugação a $13.000 \mathrm{~g}$ por $10 \mathrm{~min}$ a $4^{\circ} \mathrm{C}$. Após descarte do sobrenadante, adicionou-se $1 \mathrm{~mL}$ de etanol 75\% [em água com dietil pirocarbonato (DEPC) 0,1\%], agitando-se vigorosamente. Realizou-se a centrifugação a $8.000 \mathrm{~g}$ por $5 \mathrm{~min}$ a $4^{\circ} \mathrm{C}$, descartando-se o sobrenadante e adicionando-se $0,5 \mathrm{~mL}$ de etanol $100 \%$ para incubação por 16 horas a $-80{ }^{\circ} \mathrm{C}$. Seguiu-se nova centrifugação a 8.000 g por 5 min a $4^{\circ} \mathrm{C}$. Para permitir a secagem das amostras, o sobrenadante foi descartado e os tubos foram deixados abertos em temperatura ambiente por 5 min dentro de uma capela de fluxo laminar vertical (para impedir a contaminação das amostras). O precipitado de RNA foi ressuspenso em um volume de $12 \mu \mathrm{L}$ de água livre de DNAase e RNAase tratada com DEPC $0,1 \%$.

\subsection{Quantificação do RNA total}

A concentração de RNA total nas amostras foi determinada por diluição do RNA (fator de diluição conhecido) e leitura em cubetas de quartzo em espectrofotômetro no comprimento de onda de $260 \mathrm{~nm}$ (A260). A fórmula para calcular a concentração de RNA total foi a seguinte: $[R N A]=A 260 \times 40 \times$ fator de diluição conhecido, sendo o resultado expresso em $\mu \mathrm{g} / \mathrm{mL}$. Vale ressaltar que essa metodologia foi por nós utilizada em trabalhos recentemente publicados(OLIVEIRA et al., 2008; RODINI et al., 2008; SANTOS et al., 2009)

\subsection{Transcrição reversa}

O RNA total foi utilizado para a síntese de cDNA, o qual foi realizado utilizando o Kit Reagente para Transcrição Reversa Super-Script III (Invitrogen ${ }^{\circledR}$, Califórnia, EUA) num volume de reação de $20 \mu \mathrm{L}$ utilizando-se de 2 a $5 \mu$ g de RNA total por amostra. Os produtos da RT ( $2 \mu \mathrm{L}$ ) serviram de molde para a amplificação por PCR em tempo real (OLIVEIRA et al., 2008; RODINI et al., 2008; SANTOS et al., 2009)

\subsection{Reação em Cadeia da Polimerase (PCR) em tempo real}

O protocolo para PCR em tempo real foi feito conforme padronização estabelecida pelo Prof. Dr. Gustavo Pompermaier Garlet, colaborador deste trabalho e docente da área de Histologia da FOB/USP (GARLET et al., 2004; GARLET et al., 2006). A expressão quantitativa de genes de pró-colágeno tipo I, MIP-1 $\alpha$, SDF-1 e IL-6 foi analisada por meio de reações de PCR em tempo real, utilizando-se o sistema SYBR Green (Applied Biosystems, Foster City, USA) em um aparelho GeneAmp 7000 (Applied Biosystems, Foster City, USA). 
Primers adequados para tais reações foram criados a partir do programa Primer Express e estão listados na Tabela 1. Esse sistema realiza as reações de amplificação e detecção e quantifica as amostras ( $A B I$ Prism Software) por meio de nucleases fluorogênicas utilizadas na reação, sendo tal expressão normalizada com base em controles endógenos. Nesse trabalho, a expressão foi normalizada pelo RNAm de $\beta$-actina. O DNA complementar sintetizado a partir do RNA mensageiro foi utilizado juntamente com reagentes SYBR Green, como determinado pelo fabricante. A reação compreende $2 \mathrm{~min}$ a $50^{\circ} \mathrm{C}, 10$ minutos a $95^{\circ} \mathrm{C}$, quarenta ciclos de 15 segundos a $95^{\circ} \mathrm{C}$ e 1 minuto a $60^{\circ} \mathrm{C}$, além de um ciclo final de 20 minutos, com temperatura crescente de 60 a $95^{\circ} \mathrm{C}$ para a obtenção de uma curva de dissociação dos produtos da reação, utilizada para a análise da especificidade de amplificação. As condições de PCR para cada alvo foram cuidadosamente observadas com atenção para a concentração de primer, ausência de formação de primer-dimer, e ainda com relação à eficiência de amplificação dos genes dos alvos. Os resultados foram analisados com base no valor de CT (cicle threshold - ou ciclo limiar), sendo este o ponto correspondente ao número de ciclos a partir do qual a amplificação atinge um dado limiar que permite a análise quantitativa da expressão do fator avaliado. O limiar para positividade da PCR em tempo real foi determinado com base em controle negativo ou controle água. Os cálculos para a determinação do nível relativo de expressão gênica foram feitos conforme instrução oriunda do Boletim do Usuário (P/N 4303859) da Applied Biosystems. As médias dos valores de $\mathrm{Ct}$ de medidas em duplicata foram utilizadas para calcular a expressão do gene alvo, com normalização a um controle interno ( $\beta$-actina), e então comparados com o controle alvo-interno em grupo de células controle não estimuladas para o cálculo do aumento da expressão, utilizando a fórmula $2^{-\Delta \Delta C t}$, também de acordo com o Boletim do Usuário. 
Tabela 1. Primers e perfil da PCR de acordo com os diferentes alvos estudados.

\begin{tabular}{|c|c|c|c|}
\hline Alvo & Primers & $\begin{array}{c}\text { Temp. de desnaturação e } \\
\text { anelamento }\left({ }^{\circ} \mathrm{C}\right)\end{array}$ & Produto $(\mathrm{pb})$ \\
\hline MIP-1 $\alpha$ & $\begin{array}{l}\text { TTTGCTCTGAGAGTTCCCCCT } \\
\text { TTGGTGCCATGACTGCCTACA }\end{array}$ & $83 / 61$ & 102 \\
\hline SDF- $1 \alpha$ & $\begin{array}{l}\text { GGTTTCCGAAATCAGAAGCGA } \\
\text { TGGAACCTGAAACCCTGCTGT }\end{array}$ & $79 / 58$ & 91 \\
\hline $\begin{array}{l}\text { Colágeno } \\
\text { tipo I }\end{array}$ & $\begin{array}{l}\text { ATCTCCCCTTCGTTTTTGAGG } \\
\text { CCCCAAATCCGATGTTTCTG }\end{array}$ & $84 / 61$ & 110 \\
\hline IL-6 & $\begin{array}{l}\text { CAATAACCACCCCTGACCCAA } \\
\text { TTGTCATGTCCTGCAGCCACT }\end{array}$ & $82 / 61$ & 84 \\
\hline$\beta$-actina & $\begin{array}{l}\text { CCATCATGAAGTGTGACGTGG } \\
\text { TCTGCATCCTGTCGGCAAT }\end{array}$ & $83 / 61$ & 102 \\
\hline
\end{tabular}

\subsection{Ensaio Imunoenzimático (ELISA)}

A produção de MIP-1 $\alpha / C C L 3$, SDF-1/CXCL12 e IL-6 extracelular foi quantificada no sobrenadante das células usando o método de ensaio imunoenzimático (ELISA). Placas de 96 poços foram recobertas e incubadas com anticorpos anti-MIP-1 $\alpha$ (Anti-human CCL3/MIP-1 $\alpha$ Antibody - AF-270-NA - R\&D Systems, Minneapolis, EUA), anti-SDF-1 (Anti-human CXCL12/SDF-1 - DY350 - DuoSet Kit- R\&D Systems, Minneapolis, EUA) ou anti-IL-6 (Antihuman IL-6 monoclonal antibody 51-26451E- BD OptEIA Kit, Califórnia, EUA) diluídos em PBS (anticorpos R\&D Systems) ou tampão fosfato de cálcio (anticorpos BD). Após incubação por 16 horas, as placas foram lavadas com PBS contendo Tween 20 a 0,05\% (PBS-T) e bloqueadas durante 1 hora, em temperatura ambiente, com solução para bloqueio fornecida com os Kits. As placas, então, foram lavadas com PBS-T e incubadas com os sobrenadantes das células ou com quantidades conhecidas de MIP-1 $\alpha$, SDF-1 ou IL-6 recombinantes (R\&D Systems: MIP-1 $\alpha$ - 270-LD-010 e SDF-1-DY350-DuoSet; BD OptEIA: IL-6 51-26456E) (curvas-padrão) durante 1 hora à temperatura ambiente. Após este período, as placas foram lavadas com PBS-T e incubadas com anticorpo biotinilado (Biotynilated Anti- 
human CCL3/MIP-1 A Antibody - BAF270 R\&D Systems; Biotynilated Anti-human CXCL12/SDF-1 - DY350 R\&D Systems; Biotynilated Anti-human IL-6 51-26452) por 2h à temperatura ambiente. As placas foram lavadas com PBS-T e após a incubação por 20 min com estreptavidina as placas foram novamente lavadas e o substrato adicionado. Após 30 min a solução de paralisação da reação (ácido sulfúrico $2 \mathrm{~N}$ ) foi adicionada e a leitura foi realizada em espectrofotômetro ajustado para o comprimento de onda de $450 \mathrm{~nm}$. Esses experimentos foram realizados no Laboratório de Microbiologia e Imunologia, do Departamento de Ciências Biológicas da FOB/USP sob supervisão da $\operatorname{Prof}^{\mathrm{a}} \operatorname{Dr}^{\mathrm{a}}$ Ana Paula Campanelli.

\subsection{Imunofluorescência}

Para análise da produção de Pró-Colágeno tipo I pelos fibroblastos ligamentares humanos, as células foram semeadas com $24 \mathrm{~h}$ de antecedência sobre lamínulas circulares em placa de 24 poços e incubadas a $37^{\circ} \mathrm{C}$ com $5 \%$ de $\mathrm{CO}_{2}$ até se tornarem subconfluentes. Após fixação em acetona $\left(2 \mathrm{~min}\right.$ a $\left.-20^{\circ} \mathrm{C}\right)$, as lamínulas foram lavadas em PBS (10 vezes, de 3 min cada) e foi realizado o bloqueio com PBS 10\% Soro Bovino Fetal (SBF) (Assay Diluent BD Biosystems) por $2 \mathrm{~h}$ à temperatura ambiente. Após incubação por 16 horas com Anticorpo primário anti Pró-Colágeno tipo I diluído a 1:100 (SC25973; Santa Cruz Biotechnologies, Santa Cruz, CA, USA) a $4^{\circ} \mathrm{C}$, as células foram lavadas em PBS (10 vezes, de 3min cada), e depois incubadas com o Anticorpo Secundário Fluorescein Anti-Goat lgG $(\mathrm{H}+\mathrm{L})$ (FI-5000; Vector Laboratories, Burlingame, CA, USA) na diluição de 1:100 por 2h à temperatura ambiente. Após 10 lavagens ( $3 \mathrm{~min}$ cada) com PBS, as lamínulas foram montadas com o meio de montagem VECTASHIELD Hard-Set Mounting Medium with DAPI (H-1500; Vector Laboratories; Burlingame, CA, USA) e analisadas no microscópio confocal a laser (TCS model, SPE, Leica, Mannheim, Germany).

\subsection{Análise Estatística}

A análise estatística foi realizada utilizando o programa GraphPad Prism 5.0. As diferenças estatisticamente significativas foram determinadas por meio da análise de 
variância a 1 critério (1 way-ANOVA) seguida do pós-teste de Tukey. Foi adotado nível de significância de 5\%. 
<smiles>CCCC</smiles> 


\section{Resultados}

\#

\subsection{Cultura de Fibroblastos}

A técnica de cultura primária de fibroblastos a partir da extração de tecido gengival e de ligamento periodontal humanos se mostrou passível de reprodução durante a execução desse trabalho. A figura 1 ilustra culturas de células de ligamento periodontal (à esquerda) e de gengiva (à direita) de acordo com o tempo da cultura (imagens capturadas do microscópio óptico invertido). 
Resultados

30 
Fibroblastos de Ligamento Periodontal

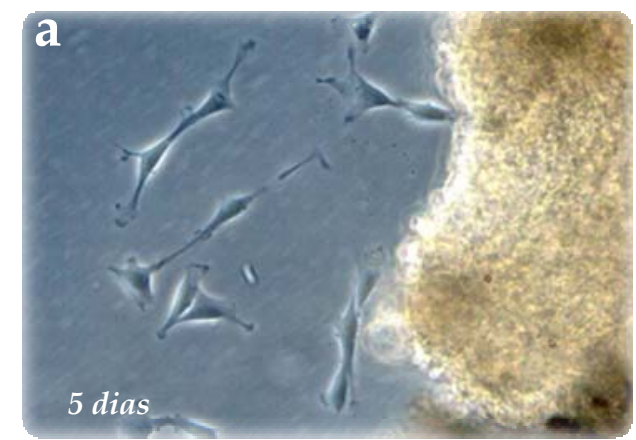

\#
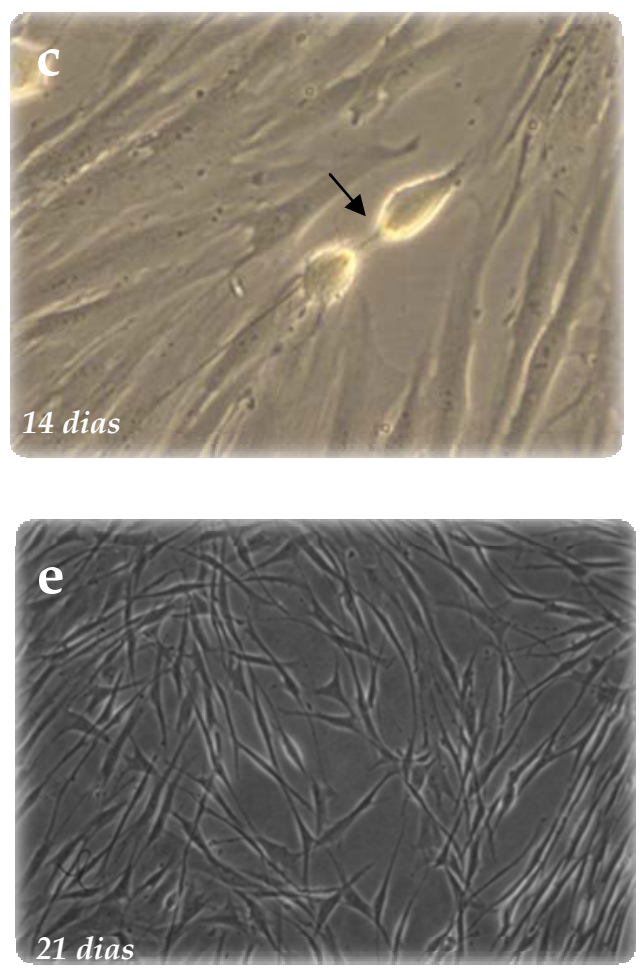

Fibroblastos de Gengiva

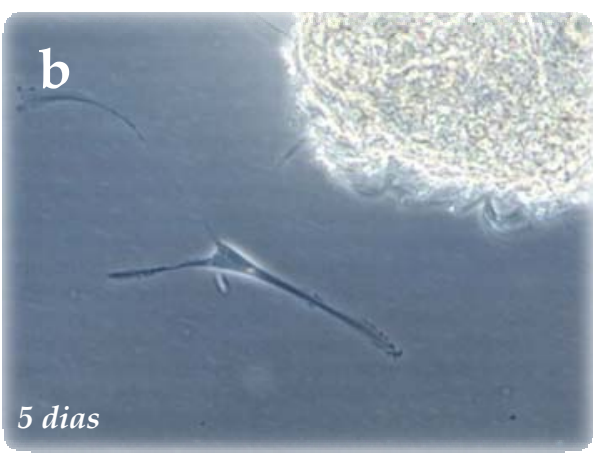

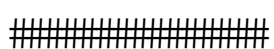
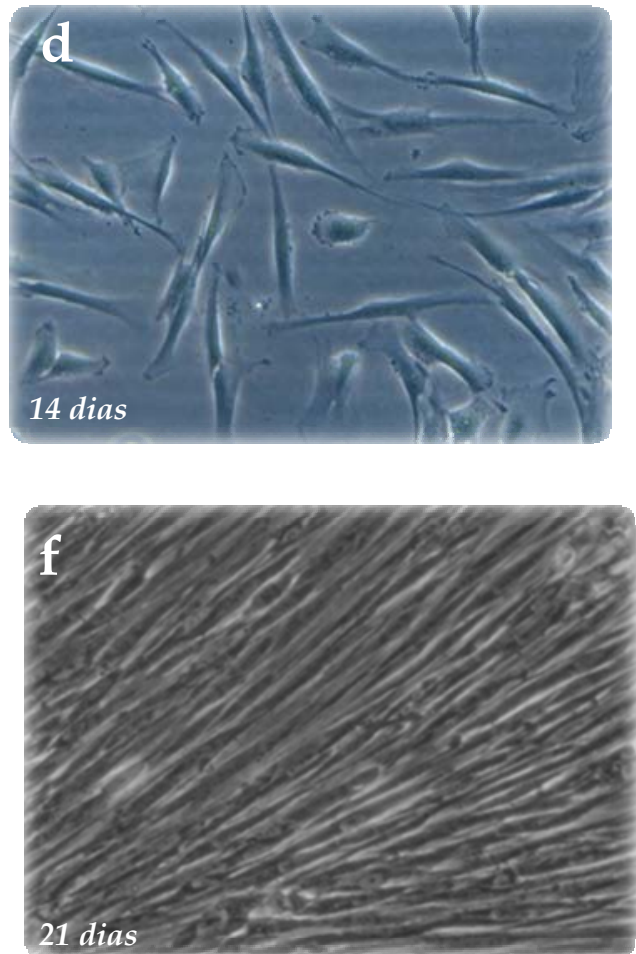

Figura 1: Cultura de Fibroblastos humanos de ligamento periodontal e de gengiva. Cultura primária obtida a partir de explants de ligamento $(a, c, e)$ e de gengiva $(b, d, f)$ do mesmo doador. Células ligamentares e gengivais com 5 dias, no início da cultura $(a, b)$, e as mesmas com 14 dias $(c, d)$. Após 21 dias apresentando-se com aspecto de confluência $(e, f)$. Visualização em microscópio óptico invertido com aumento de 100X $(a, b, e, f)$ e de 300X $(c, d)$. Em $d$, observamos as células em mitose (seta). 


\subsection{Análise de Pró-Colágeno tipo I por PCR em tempo real e imunofluorescência}

A expressão gênica relativa (normalizada pela $\beta$-actina) de Pró-Colágeno tipo I foi avaliada por PCR em tempo real. Os fibroblastos do ligamento periodontal apresentaram uma tendência de produção constitutiva que se manteve constante ao longo dos tempos de análise e não se alterou com as diferentes concentrações de estímulo (Figura 2-a). Já os fibroblastos gengivais, com as concentrações de 0,1 e $1 \mu \mathrm{g} / \mathrm{ml}$ tiveram uma queda nessa produção constitutiva que foi retomada e até maior na concentração de $10 \mu \mathrm{g} / \mathrm{ml}$ (Figura 2b). Para os fibroblastos ligamentares, o grupo controle com $24 \mathrm{~h}$ foi analisado por imunofluorescência para confirmar síntese protéica de pró-colágeno tipo I. Como mostrado pela Figura 3-a, os fibroblastos ligamentares exibiram intensidade de fluorescência verde no citoplasma, compatível com a produção de pró-colágeno, e em azul foi observada a marcação dos núcleos com DAPI. Já no controle negativo, o qual não recebeu o anticorpo primário, não foi detectada fluorescência (Figura 3-b). Este resultado confirma a caracterização das células cultivadas como fibroblastos.
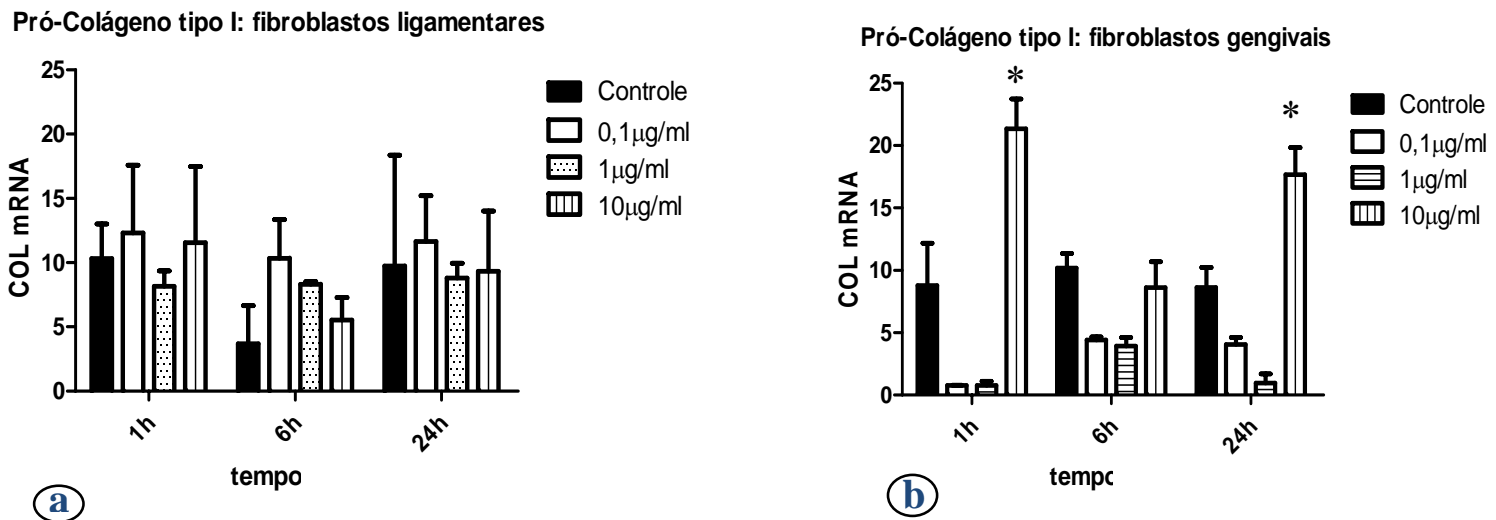

Figura 2. Expressão de RNAm para Pró-Colágeno tipo I(COL) por fibroblastos humanos de ligamento periodontal e de gengiva estimulados por LPS de $\underline{P \text { gingivalis. }}$ Culturas primárias foram estabelecidas a partir de tecidos de 3 indivíduos saudáveis e após a $4^{\text {a }}$ passagem foram estimuladas com LPS de $P$ gingivalis nas concentrações de $0,1,1$ e $10 \mu \mathrm{g} / \mathrm{ml}$. RNA total foi extraído da cultura de fibroblastos gengivais e de ligamento periodontal e a expressão de Pró-colágeno tipo I foi analisada por PCR em tempo real. A expressão de RNAm foi quantificada em relação ao controle interno $\beta$-actina. ${ }^{*} \mathrm{P}<0,05$ comparado às demais concentrações de estímulo no mesmo tempo experimental. 
Resultados

34 

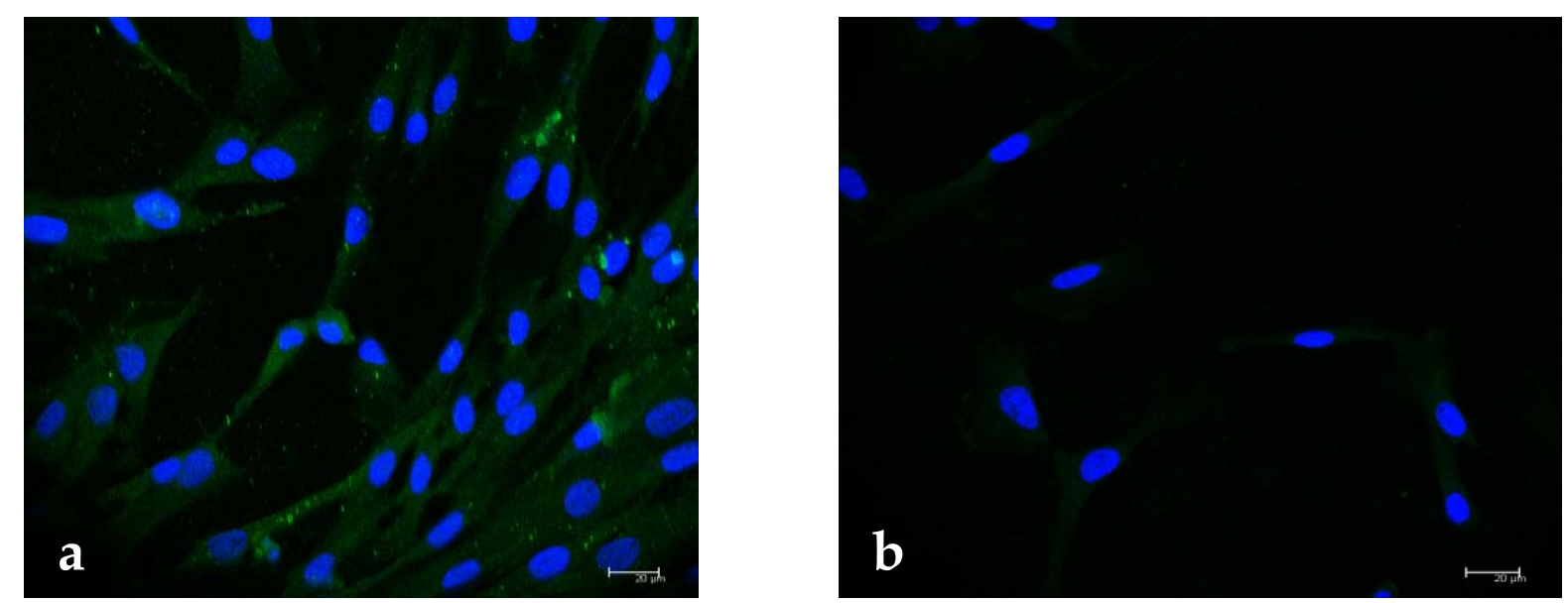

Figura 3. Detecção da produção de Pró-Colágeno tipo I em fibroblastos de ligamento periodontal por imunofluorescência. Para confirmação da síntese protéica de pró-colágeno tipo I, foi realizada marcação desta proteína por imunofluorescência em células de ligamento periodontal (controle - 24h). A marcação verde indica a presença Pró-colágeno tipo I no citoplasma e os núcleos são corados em azul (marcação DAPI) (a). Em $b$, controle negativo. 


\subsection{Expressão de MIP-1a, SDF-1 e IL-6 por fibroblastos gengivais e ligamentares por PCR em tempo real}

A expressão relativa de RNAm para MIP-1 $\alpha$, SDF-1 e IL-6 também foi analisada por PCR em tempo real. Fibroblastos gengivais, tanto para MIP-1 $\alpha$ (Figura 4-b) como para SDF-1 (Figura 5-b) demonstraram uma pequena expressão basal (controle) que foi notadamente inibida com as concentrações de 0,1 e $1 \mu \mathrm{g} / \mathrm{ml}$ de LPS e estimulada com $10 \mu / \mathrm{ml}$ (diferença estatisticamente significante) nos tempos experimentais de $1 \mathrm{~h}$ e $24 \mathrm{~h}$. Entretanto, quando foi avaliado o comportamento das células do ligamento periodontal dos mesmos indivíduos, não houve diferença significativa na expressão dessas quimiocinas entre as diferentes concentrações de estímulo e nos diferentes tempos experimentais. Houve apenas a manutenção dos níveis de expressão de RNAm ao longo do tempo em relação ao gene constitutivo utilizado como controle interno ( $\beta$-actina, Figuras 4-a e 5-a).

Em relação à citocina IL-6, tanto para as células provenientes de gengiva quanto para as de ligamento periodontal, não foram observadas diferenças significativas quanto à expressão gênica dessa citocina. Foi detectada apenas uma discreta tendência a uma maior expressão de RNAm no tempo de $1 \mathrm{~h}$ com $10 \mu \mathrm{g} / \mathrm{ml}$ de LPS na célula gengival, exatamente o oposto do que ocorreu no grupo correspondente para ligamento periodontal (Figura 6). 


\section{MIP-1 alpha: fibroblastos ligamentares}

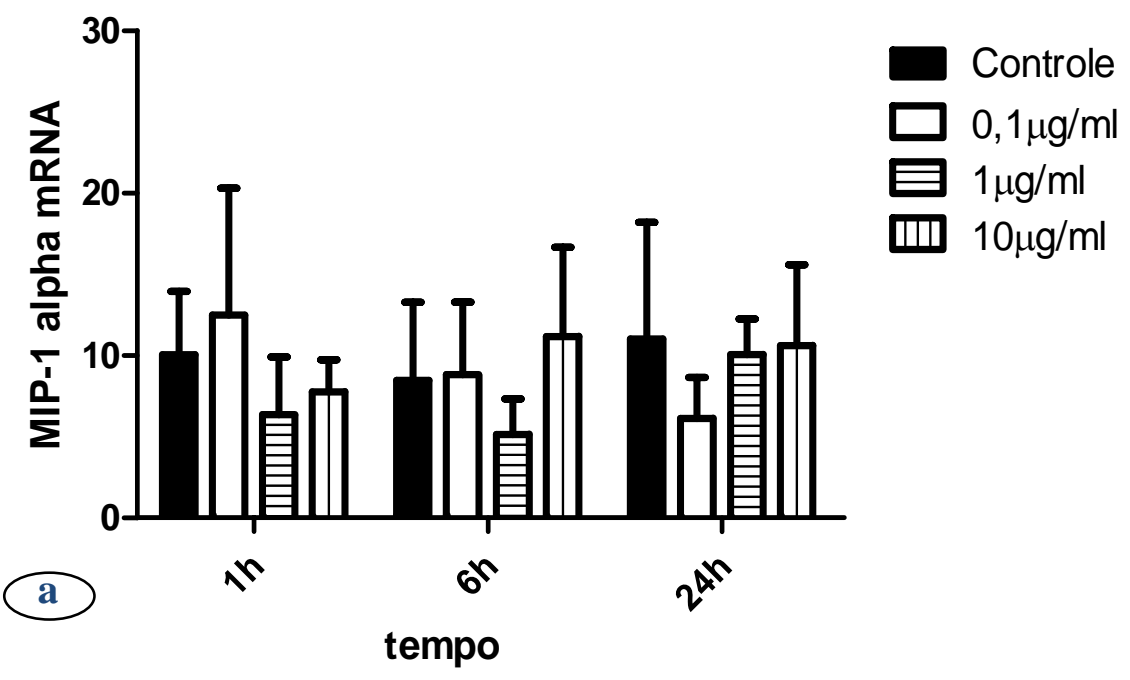

MIP-1 alpha: fibroblastos gengivais

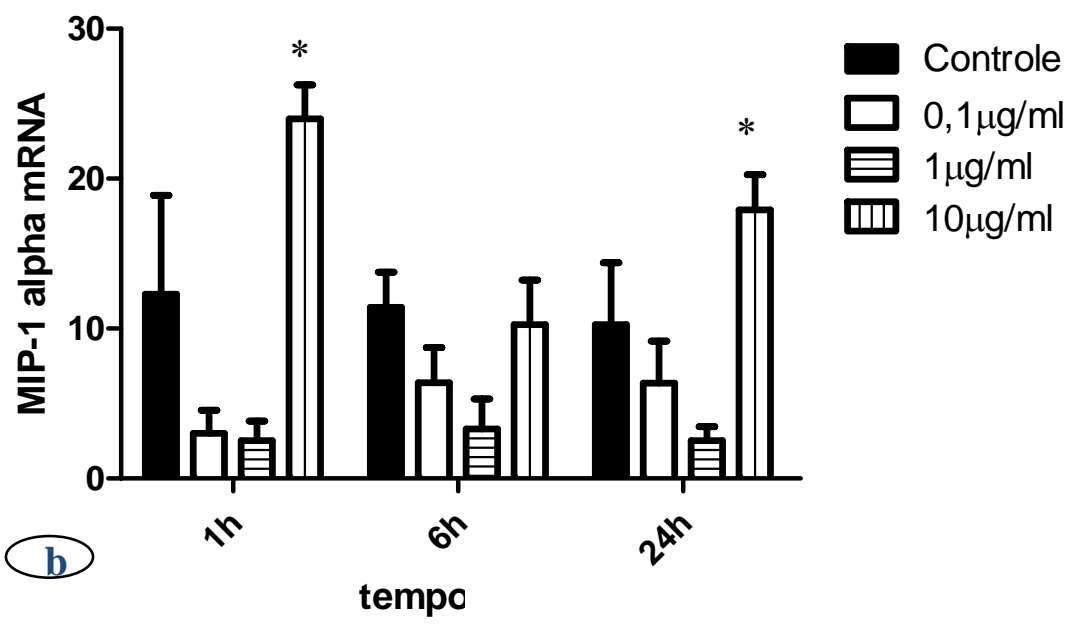

Figura 4. Expressão de RNAm para MIP-1a por fibroblastos de ligamento periodontal e de gengiva estimulados por LPS de $\underline{P}$ gingivalis. As culturas primárias foram estabelecidas a partir dos tecidos de 3 indivíduos saudáveis e, após a $4^{\mathrm{a}}$ passagem, foram estimuladas com LPS de $P$ gingivalis nas concentrações de 0,$1 ; 1$ e $10 \mu \mathrm{g} / \mathrm{ml}$. Como controle, foi utilizado o meio de cultura sem estímulo. RNA total foi extraído da cultura de fibroblastos gengivais e de ligamento periodontal e a expressão de MIP-1 $\alpha$ foi analisada por PCR em tempo real. A expressão de RNAm foi quantificada em relação ao controle interno $\beta$-actina. $* \mathrm{P}<0,05$ comparado às demais concentrações de estímulo no mesmo tempo experimental. 
SDF-1: fibroblastos ligamentares

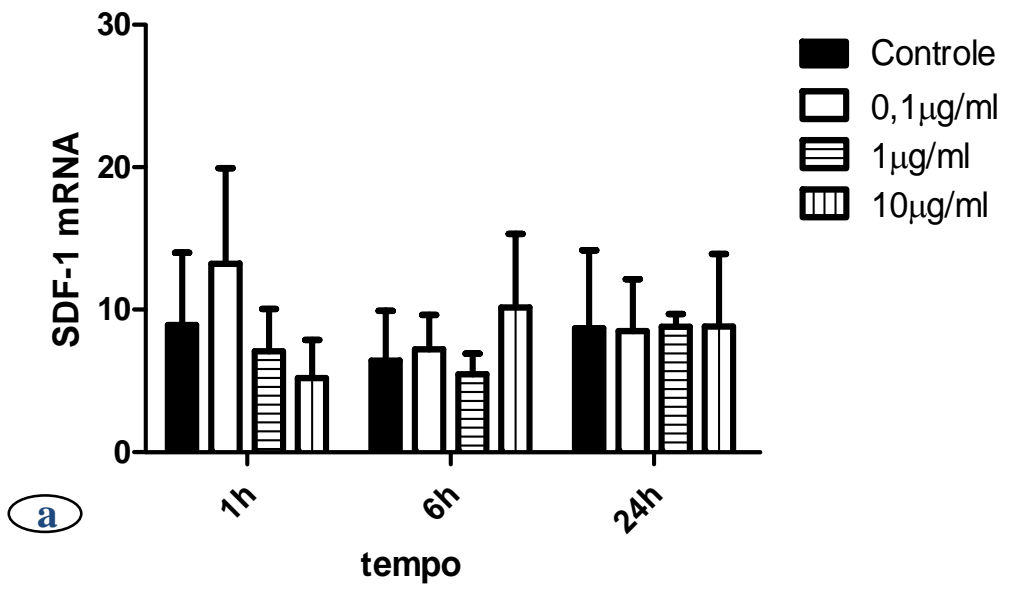

SDF-1: fibroblastos gengivais

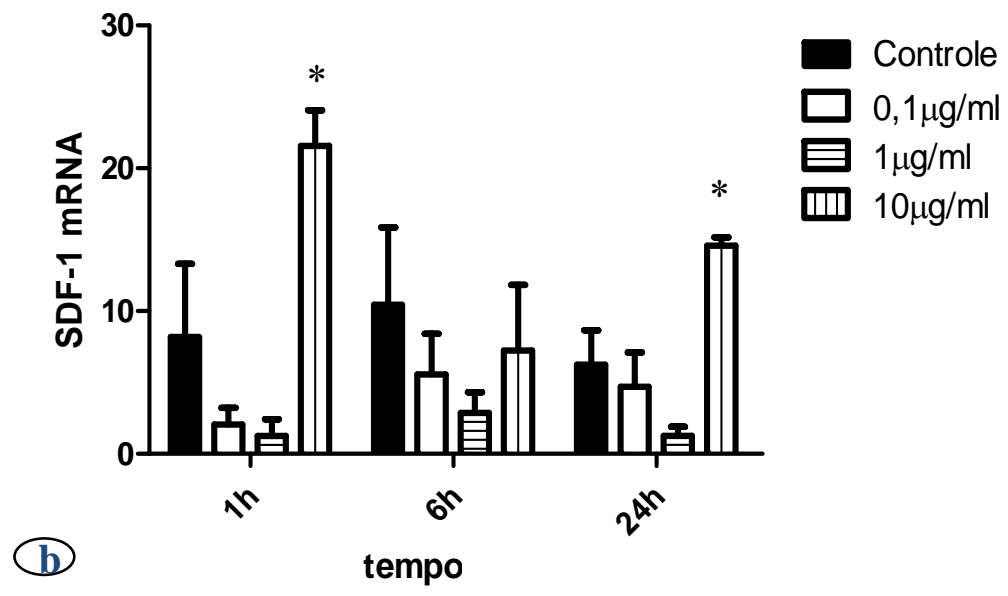

Figura 5. Expressão de RNAm para SDF-1 por fibroblastos de ligamento periodontal e de gengiva estimulados por LPS de $\underline{P}$ gingivalis. As culturas primárias foram estabelecidas a partir dos tecidos de 3 indivíduos saudáveis e, após a $4^{\mathrm{a}}$ passagem, foram estimuladas com LPS de P gingivalis nas concentrações de 0,1;1 e $10 \mu \mathrm{g} / \mathrm{ml}$. Como controle, foi utilizado o meio de cultura sem estímulo. RNA total foi extraído da cultura de fibroblastos gengivais e do ligamento periodontal e a expressão de SDF-1 foi analisada por PCR em tempo real. A expressão de RNAm foi quantificada em relação ao controle interno $\beta$-actina. ${ }^{*} \mathrm{P}<0,05$ comparado às demais concentrações de estímulo no mesmo tempo experimental. 
IL-6: fibroblastos ligamentares

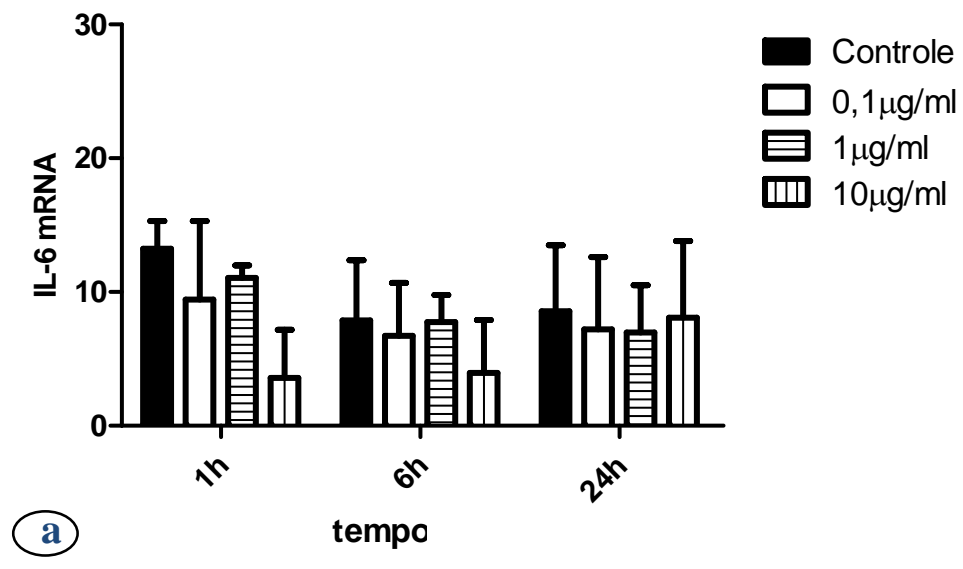

\section{IL-6: fibroblastos gengivais}

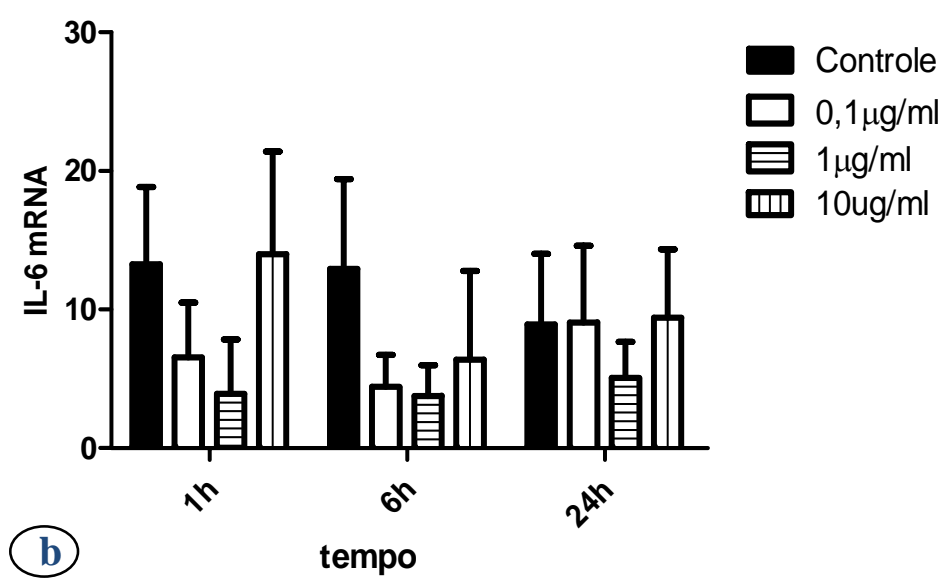

Figura 6. Expressão de RNAm para IL-6 por fibroblastos de ligamento periodontal e de gengiva desafiados por LPS de $\underline{P}$ gingivalis. As culturas primárias foram estabelecidas a partir dos tecidos de 3 indivíduos saudáveis e, após a $4^{\mathrm{a}}$ passagem, foram estimuladas com LPS de $P$ gingivalis nas concentrações de 0,$1 ; 1$ e $10 \mu \mathrm{g} / \mathrm{ml}$. Como controle, foi utilizado o meio de cultura sem estímulo. RNA total foi extraído da cultura de fibroblastos gengivais e de ligamento periodontal e a expressão de IL-6 foi analisada por PCR em tempo real. A expressão de RNAm foi quantificada em relação ao controle interno $\beta$-actina. 
Resultados

44 


\subsection{Detecção da produção de MIP-1a, SDF-1 e IL-6 por fibroblastos gengivais e ligamentares por ELISA}

A produção de MIP-1 $\alpha$, SDF-1 e IL-6 foi detectada a partir do sobrenadante das células em cultura por ELISA. A análise mostrou que fibroblastos de gengiva e ligamento periodontal se comportaram de maneira diferente quanto à produção de IL-6, MIP-1 $\alpha$ e SDF-1 ao longo dos tempos experimentais, sendo que para os três alvos foi observado que as células gengivais produziram praticamente o dobro das citocinas quando comparadas às células ligamentares. Dentre as citocinas estudadas, os níveis de produção de MIP-1 $\alpha$ foram os mais baixos para as células provenientes de ambos os tecidos. Para essa quimiocina, houve um pico de produção na concentração mais baixa de estímulo $(0,1 \mu \mathrm{g} / \mathrm{ml})$ nos fibroblastos gengivais que foi estatisticamente significativa $(P<0,05)$ quando comparada às demais concentrações. Ainda analisando a concentração de $0,1 \mu \mathrm{g} / \mathrm{ml}$, observou-se que esta se mostra crescente ao longo dos tempos experimentais ( $6 \mathrm{~h}$ e $24 \mathrm{~h}$ ) em relação à primeira hora. Entretanto, a sua produção por fibroblastos ligamentares foi bem discreta e sem diferenças significativas entre os grupos experimentais (Figura 7).

Para SDF-1, em ambos os tecidos, houve produção constitutiva estatisticamente significativa com $24 \mathrm{~h}$ quando comparada aos tempos de $1 \mathrm{~h}$ e $6 \mathrm{~h}(\mathrm{P}<0,05)$ e uma queda dessa produção com estímulo de $10 \mu \mathrm{g} / \mathrm{ml}$ de LPS $(P<0,05)$, que nas células gengivais foi mais acentuada (Figura 8).

A produção de IL-6 foi muito discreta na primeira hora de estímulo, mas se mostrou crescente ao longo do tempo e com o aumento da concentração de LPS para fibroblastos ligamentares, sendo estatisticamente significativa com $10 \mu \mathrm{g} / \mathrm{ml}$ no tempo de $6 \mathrm{~h}(P<0,05)$. A mesma tendência foi observada no tempo de $24 \mathrm{~h}$, porém sem diferenças estatísticas entre as concentrações. Da mesma forma, para a gengiva, a produção foi significativamente maior com $6 \mathrm{~h}$ e $24 \mathrm{~h}$ em relação à primeira hora $(P<0,05)$, porém sem diferenças entre as concentrações de estímulo, apesar de apresentar uma tendência a aumentar juntamente com a concentração de LPS (Figura 9). 
MIP-1 $\alpha$ : fibroblastos ligamentares

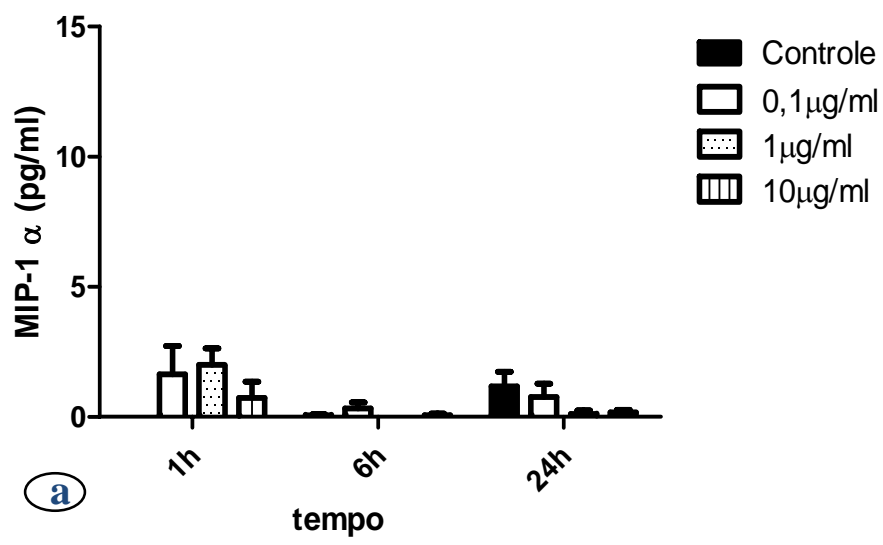

MIP-1 $\alpha$ : fibroblastos gengivais

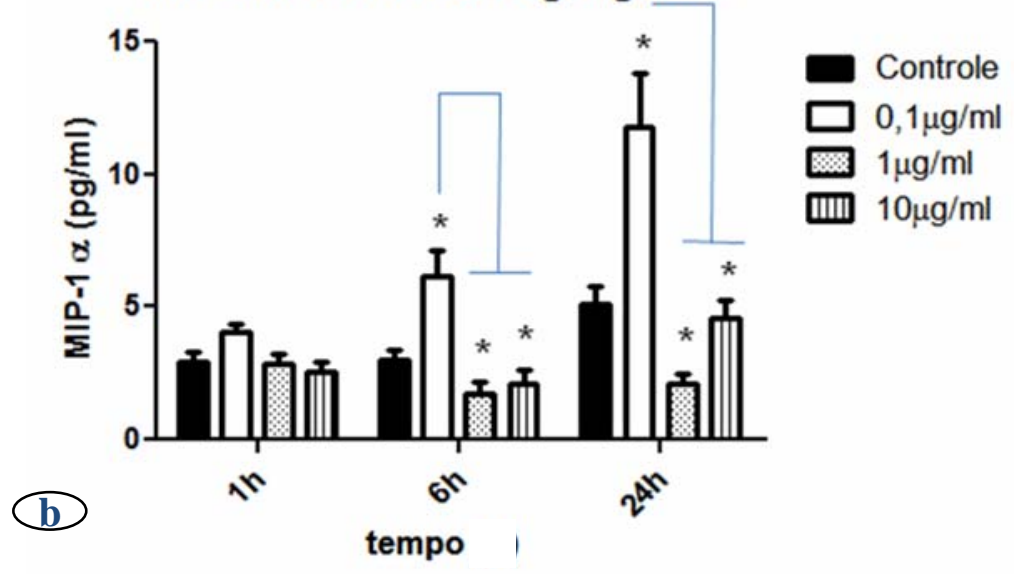

Figura 7. Produção de MIP-1a por fibroblastos de ligamento periodontal e de gengiva desafiados por LPS de P gingivalis. As culturas primárias foram estabelecidas e após a $4^{a}$ passagem foram estimuladas com LPS de $P$ gingivalis nas concentrações de 0,1 , 1 e $10 \mu \mathrm{g} / \mathrm{ml}$. Como controle foi utilizado o meio de cultura sem estímulo. Para a quantificação de MIP-1 $\alpha$ nos sobrenadantes foi utilizada a técnica de ensaio imunoenzimático (ELISA). 

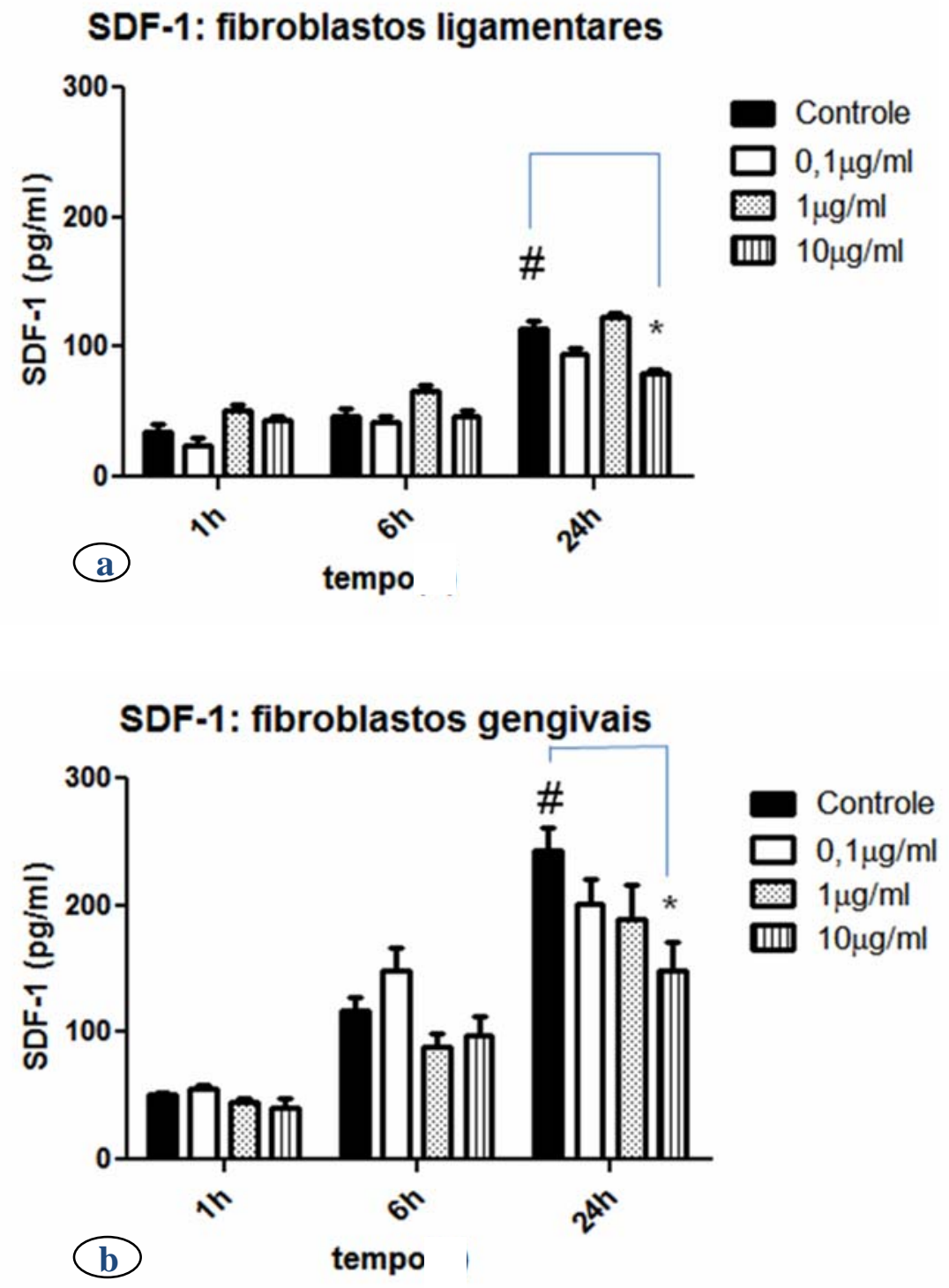

Figura 8. Produção de SDF-1 por fibroblastos de ligamento periodontal e de gengiva estimulados por LPS de $\mathrm{P}$ gingivalis. As culturas primárias foram estabelecidas e após a $4^{\text {a }}$ passagem foram estimuladas com LPS de $P$ gingivalis nas concentrações de 0,1 , 1 e $10 \mu \mathrm{g} / \mathrm{ml}$. Como controle foi utilizado o meio de cultura sem estímulo. Para a quantificação de SDF-1 nos sobrenadantes foi utilizada a técnica de ensaio imunoenzimático (ELISA) * $\mathrm{P}<0,05$ comparado às demais concentrações de estímulo no mesmo tempo experimental. ${ }^{\#} \mathrm{P}<0,05$ comparado aos demais tempos de estímulo. 
Resultados

50 

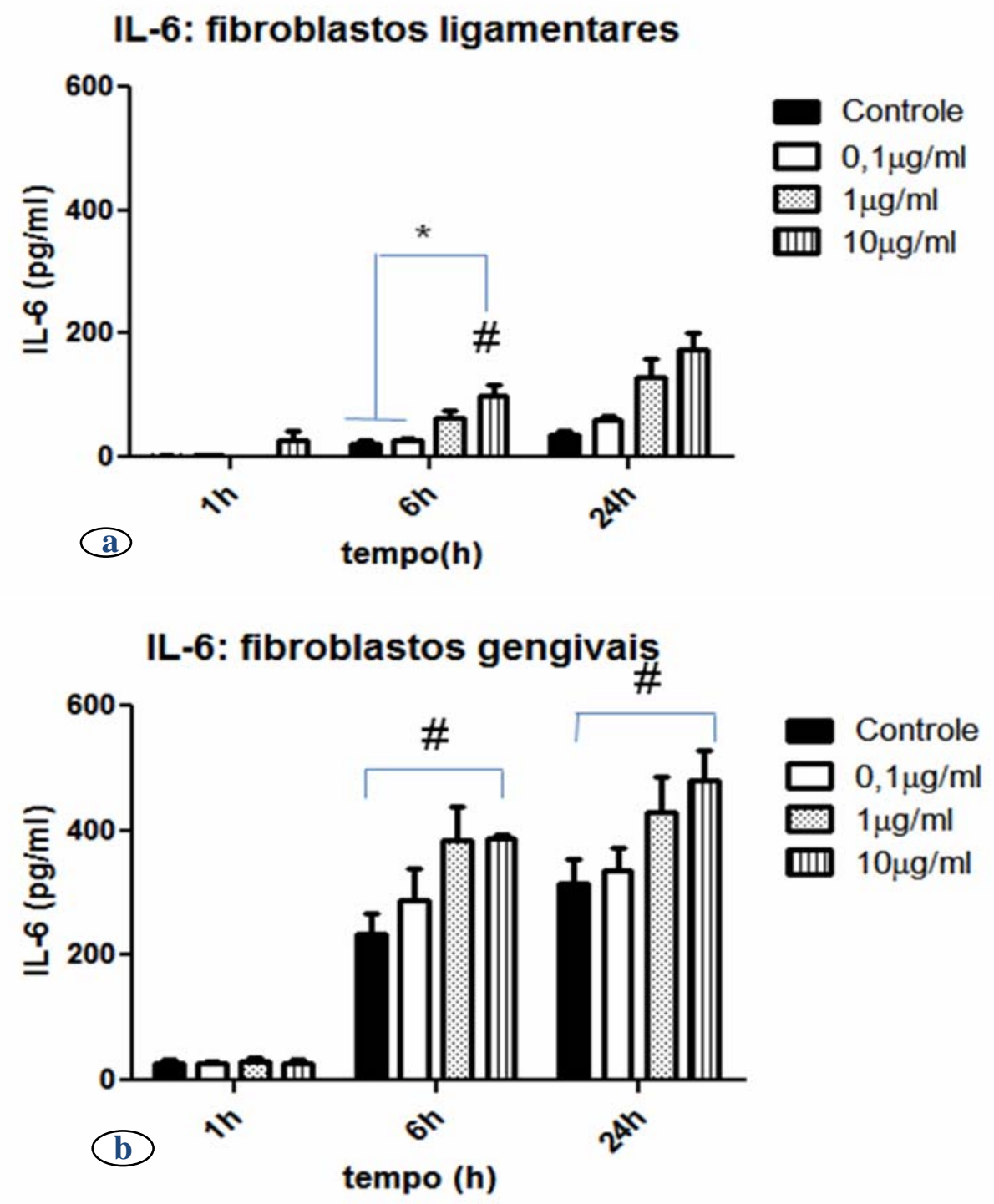

Figura 9. Produção de IL-6 por fibroblastos de ligamento periodontal e de gengiva estimulados por LPS de P gingivalis. As culturas primárias foram estabelecidas e após a $4^{\mathrm{a}}$ passagem foram estimuladas com LPS de $P$ gingivalis nas concentrações de 0,1 , $1 \mathrm{e} 10 \mu \mathrm{g} / \mathrm{ml}$. Como controle foi utilizado o meio de cultura sem estímulo. Para a quantificação de IL-6 nos sobrenadantes foi utilizada a técnica de ensaio imunoenzimático (ELISA). ${ }^{*} \mathrm{P}<0,05$ comparado às demais doses de estímulo no mesmo tempo experimental. ${ }^{*} \mathrm{P}<0,05$ comparado aos demais tempos de estímulo. 



\section{Discussão}

\#

A participação dos fibroblastos nos fenômenos inflamatórios e imunológicos em função da capacidade destas células de produzirem citocinas, dentre elas quimiocinas, além de outros agentes pró-inflamatórios, vem sendo estudada por diversos autores (TAKASHIBA et al., 1992) já que é bem elucidado o fato de que os fibroblastos não constituem um grupo celular único entre diferentes regiões anatômicas \{Brouty-Boye, 2000 \#104; YAMAJl et al., 1995; WANG et al., 1998; WANG et al., 1999; BROUTY-BOYE et al., 2000; SUGIYAMA et al., 2000; FEDYK et al., 2001; HATAKEYAMA et al., 2003; OGURA et al., 2005; MAHANONDA et al., 2007; UEHARA; TAKADA, 2007). A escolha por trabalhar com estímulo proveniente de $P$. gingivalis neste trabalho deveu-se principalmente à importância que esse microrganismo assume na etiopatogenia da doença periodontal. A maior contribuição para o aumento da severidade da doença é proveniente das bactérias do complexo vermelho, sendo a Porphyromonas gingivalis uma das mais comprometedoras para a situação de periodontite (OFFENBACHER et al., 2007; OFFENBACHER; BARROS; BECK, 2008). Grande parte dos modelos experimentais in vivo e in vitro utilizam LPS de $P$ gingivalis como desafio antigênico relacionado à doença periodontal. (CHEN et al., 2008; HAVENS et al., 2008; ZHANG et al., 2008)

Dada a importância de se conhecer mais sobre o papel dos fibroblastos gengivais e ligamentares quanto ao seu comportamento frente à infecção periodontal, o presente estudo procurou investigar as características destes quanto à produção de pró-colágeno tipo I, uma vez que esta molécula é precursora para o colágeno tipo I, ou seja, o colágeno predominante na matriz extracelular do ligamento periodontal, fundamental para manutenção da homeostasia ligamentar (FIORELLINI; KIM; ISHIKAWA, 2006). Nossos dados mostram a produção constitutiva de pró-colágeno desde a primeira hora de estímulo sem alterações significativas ao longo do tempo experimental ou qualquer mudança em relação à quantidade de LPS de $P$ gingivalis administradas às culturas de fibroblastos do ligamento, uma vez que essa é a função primordial desta célula e portanto não nos surpreende o fato de que ela, mesmo mediante ao desafio bacteriano, continue expressando RNAm para o Pró-Colágeno tipo I. Por outro lado, essa concentração de estímulo bacteriano pode não ter sido tão crítica a ponto de induzir alguma alteração na expressão constitutiva do gene para Pró-Colágeno tipo I. Já foi demonstrada a maior expressão relativa de Pró-Colágeno tipo I 
por fibroblastos ligamentares quando comparados aos gengivais (KURU et al., 1998). Há indícios de uma sensibilidade maior dessas células com estímulos de natureza mecânica, como por exemplo sinais mecânicos de indução de força, simulando movimento ortodôntico, que foram relacionados com a ativação e aumento da expressão gênica de prócolágeno tipo I por fibroblastos de ligamento periodontal (KOOK et al., 2009). Em relação aos fibroblastos gengivais, essa mesma expressão constitutiva na primeira hora de estímulo sofreu uma queda, em todos os tempos experimentais, com as concentrações de 0,1 e $1 \mu \mathrm{g} / \mathrm{ml}$. A produção de pró-colágeno tipo I foi recuperada e até mesmo mais expressiva com 24h. Podemos dizer, desta forma, que os fibroblastos gengivais demonstraram uma maior sensibilidade, se comparados às células ligamentares do mesmo doador, frente ao desafio por LPS de $P$ gingivalis quanto à expressão constitutiva de pró-colágeno tipo I.

A produção aumentada de citocinas e quimiocinas por fibroblastos em decorrência do desafios microbianos tem sido documentada na literatura. Hosokawa et al, em 2005, mostraram um aumento na produção de IL-8 por fibroblastos gengivais estimulados por $P$. gingivalis morta por calor. Outros autores relataram a alteração da produção constitutiva de citocinas após a colocação de microrganismo como desafio aos fibroblastos, sugerindo a possível ocorrência do reconhecimento de antígenos pelas células em cultura (MAHANONDA et al., 2007; UEHARA; TAKADA, 2007). Foi documentada a presença de receptores CD14 em fibroblastos gengivais comprovando a capacidade destes receptores em se ligar a LPS de $P$ gingivalis (WANG et al., 1998). O bloqueio com anti-CD14 diminuiu a produção de IL-6, o que sugere a presença desse receptor no reconhecimento de antígenos por fibroblastos gengivais. Foi demostrada também a expressão de receptores do tipo Toll 4 ( Toll like receptor - TLR 4) em fibroblastos humanos de ligamento periodontal (SUN et al., 2008). Ao comparar fibroblastos gengivais e ligamentares do mesmo indivíduo (HATAKEYAMA et al., 2003) demonstraram expressão mais elevada de CD14 por fibroblastos de gengiva, expressão de TLR2 discretamente mais elevada por fibroblastos de ligamento periodontal e expressão semelhante de TLR4 por ambos os grupos de células. (MAHANONDA et al., 2007) demonstraram a expressão dos receptores TLR1, TLR2, TLR3, TLR4, TLR5, TLR6 e TLR9, mostrando que ligantes específicos para TLRs 2, 3, 4 e 5 levaram ao aumento significativo da produção de IL-8 pelas células. Em estudo semelhante, mostrou-se a expressão de TLR1-9, MD-2, MyD88, NOD1 e NOD2 (moléculas reconhecedoras de antígenos) (UEHARA; TAKADA, 2007). E ainda, o tratamento com LPS aumentou em mais de 
duas vezes a expressão de 12 genes, incluindo TLR4, TLR5 e TLR7 e IL-6 de maneira TLR4 dependente (SUN et al., 2008).

A respeito da quimiocina MIP-1 $\alpha$, que foi um dos alvos do nosso trabalho, é importante ressaltar seu papel particularmente interessante, pois foi demonstrado que MIP$1 \alpha$ é requerida para que haja uma resposta inflamatória normal e que uma de suas propriedades biológicas é a inibição da proliferação de células-tronco hematopoiéticas in vitro e in vivo (COOK, 1996). Recentemente foi sugerido seu papel como possível biomarcador para a periodontite agressiva localizada (FINE et al., 2009). Sua produção também foi demonstrada por células epiteliais gengivais como evento importante no início da inflamação e facilitação da ativação e acúmulo de leucócitos. Foi sugerido que MIP-1 $\alpha$ poderia ser importante desde os estágios mais precoces até os mais avançados da periodontite por estar associado à possível formação de células ósseas multinucleadas (RYU et al., 2007). Os resultados desses autores não corroboram os nossos achados de produção dessa quimiocina por fibroblastos gengivais. Nossos resultados quanto à produção de MIP$1 \alpha$ foram bem claros ao demonstrar a diferença existente entre a produção desta quimiocina por fibroblastos ligamentares e gengivais. Enquanto as células do ligamento tiveram uma produção muito discreta de MIP-1 $\alpha$, quase não detectável e não mutável ao longo do tempo, as células gengivais exibiram aumento de expressão tempo-dependente, sendo estatisticamente significativa às $6 \mathrm{~h}$ e $24 \mathrm{~h}$ com a menor concentração de estímulo. Ao nos depararmos com esse resultado, somos levados à sugerir que talvez essa quimiocina esteja sendo produzida mais expressivamente com baixas doses de LPS, como característica de uma resposta inflamatória de fase crônica, que com o aumento da concentração de LPS leva a uma inibição também significativa desta quimiocina, que poderia ser entendida como um mecanismo de compensação para a produção de outras citocinas e/ou quimiocinas que sejam características de um microambiente inflamatório agudo. Notamos, por exemplo, que a IL-6 se mostrou aumentada quando os níveis de MIP-1 $\alpha$ estavam baixos. A expressão de RNAm para MIP-1 $\alpha$ coincide com os nossos resultados pra SDF-1 tanto no tecido gengival quanto ligamentar, sendo então que, em relação à expressão gênica podemos assumir que existe um padrão entre MIP-1 $\alpha$ e SDF-1.

Nossos dados demonstraram que SDF-1 foi produzida por fibroblastos provenientes de tecidos periodontais clinicamente normais. Observamos ainda que essa produção ocorreu principalmente no período de $24 \mathrm{~h}$, sendo que provavelmente nos períodos 
anteriores, apesar de já haver a expressão gênica, ou seja, o sinal para a produção dessa quimiocina, a resposta celular para a produção efetiva da proteína foi mais demorada, principalmente para os fibroblastos ligamentares. Experimentos in vitro mostraram a produção dessa quimiocina por fibroblastos não estimulados. Há relatos de que haja realmente uma expressão basal de RNAm (LUSTER, 1998), bem como a produção da quimiocina por ELISA (HOSOKAWA et al., 2005) pelos tecidos saudáveis, que corroboram os nossos achados. A produção de SDF-1 pode, dessa forma, estar relacionada à condição fisiológica em tecidos periodontais normais. A aplicação do estímulo culminou com a inibição significativa da produção da proteína de maneira concentração-dependente no período de $24 \mathrm{~h}$ em ambos os tecidos, sendo até mais severa nos fibroblastos do tecido gengival, o que também foi previamente relatado no trabalho de (HOSOKAWA et al., 2005). Contudo, não encontramos essa inibição da expressão de RNAm como seria o esperado em nenhum dos dois tecidos.

Os resultados comparativos entre expressão gênica e síntese protéica demonstraram perfil diferencial entre estes alvos. Em relação à expressão gênica, observamos o aumento significativo com a concentração de $10 \mu \mathrm{g} / \mathrm{ml}$ nas células provenientes do tecido gengival, o que nos faz pensar na ocorrência de eventos pós-transcricionais regulatórios. Pouco se sabe à respeito do papel da regulação pós-transcricional da expressão gênica no desenvolvimento e função das células. Uma das possibilidades de mediação desse processo é uma abundante classe de pequenos RNAs não-codificadores de aproximadamente 22 nucleotídeos, conhecidos como microRNAs (miRNAs), que seriam capazes de regular a expressão de genes em um nível pós-transcricional por afetar a degradação e translação do RNAm alvo (LODISH et al., 2008) e que, em última análise, poderiam regular a síntese da proteína. Comparado a outros mecanismos regulatórios da expressão gênica, como a modificação de cromatina e controle transcricional, a regulação gênica mediada por miRNA ocorre em um estágio imediatamente anterior à síntese protéica, e então pode ser mais compatível com o ajuste fino da expressão gênica e da regulação quantitativa (BARTEL; CHEN, 2004).

Considerando que a detecção da produção da proteína é soberana, o efeito inibitório da produção de SDF-1 que encontramos com o estímulo e o aumento da dose de LPS de $P$. gingivalis poderia contribuir para o processo de doença, uma vez que pode ser um indício de que esteja ocorrendo uma modulação para a produção de outras citocinas pró- 
inflamatórias, como IL-6 por exemplo, que poderia ser explicado a partir da investigação a respeito da disponibilidade de ligação dos receptores envolvidos. Foi demonstrado que os níves de SDF-1 se alteram em resposta à inflamação periodontal (HAVENS et al., 2008). O fluido crevicular gengival de sítios apresentando maior perda de inserção clínica apresentaram níveis dessa quimiocina significativamente maiores do que os sítios classificados como saudáveis. Além disso, estudos prévios haviam mostrado a responsividade de leucócitos ao SDF-1 $\alpha$ (LENOIR; DJERDJOURI; PERIANIN, 2004; LINK, 2005; KIM et al., 2007). Diante destes nossos resultados e concordando com outros autores, podemos sugerir que SDF-1 é expresso sob condições basais, sendo que sua produção pode ser modificada por mediadores inflamatórios, como outras citocinas presentes no microambiente inflamatório. Sendo assim, podemos sugerir que SDF-1 teria um papel importante na resposta dos fibroblastos dentro do contexto da inflamação periodontal.

Como já observado para as quimiocinas, a produção de IL-6 foi mais discreta no ligamento periodontal, sendo que, ainda assim, pudemos observar um padrão de comportamento concentração e tempo dependente, evidenciando a importância dessa citocina no ambiente inflamatório periodontal. IL-6 é uma citocina pleiotrópica capaz de estimular a reabsorção óssea e expressa por vários tipos celulares. Foi detectado um aumento da expressão gênica da citocina IL-6 por fibroblastos gengivais humanos em uma estimulação concentração-dependente por IL-1ß e TNF- $\alpha$ (PALMQVIST et al., 2008). Da mesma forma, culturas primárias derivadas de tecido gengival de camundongos foram expostas ao LPS de $P$ gingivalis e a produção de IL-6, bem como de TNF- $\alpha$ foi significativamente elevada (EKHLASSI et al., 2008). A indução da expressão de IL-6 frente ao desafio microbiano, por meio do LPS, também foi significante por fibroblastos do ligamento periodontal (SUN et al., 2008), evidenciando a importância e a participação dessa citocina nos eventos inflamatórios de ambos os tecidos. Da mesma forma, os nossos resultados evidenciam um aumento significativo da produção de IL-6 por fibroblastos gengivais, a partir de $6 h$, que se mantém com $24 h(P<0,05)$. É importante ressaltar que houve uma tendência visível de produção dependente da concentração de LPS, apesar de não termos observado diferenças significativas entre as concentrações nesses tempos de estímulo para as células gengivais. Acreditamos que a não detecção da produção de IL-6 na primeira hora de estímulo tenha ocorrido por ser um período muito precoce para a deteç̧ão desta citocina, 
mas ressaltamos a expressão gênica já existente neste tempo, mantida constante, tanto por fibroblastos de gengiva quanto por células ligamentares.

Os resultados deste trabalho indicam que as células do ligamento periodontal exibem características significativamente distintas em relação aos fibroblastos gengivais in vitro. Outros trabalhos também mostraram que embora existam similaridades nas características de crescimento e morfologia entre fibroblastos ligamentares e gengivais, estas mesmas células exibem diferenças funcionais específicas na síntese de macromoléculas e na síntese protéica (MARIOTTI; COCHRAN, 1990; GIANNOPOULOU; CIMASONI, 1996; KURU et al., 1998). É importante ressaltar que as diferenças relatadas aqui foram consistentemente observadas para os fibroblastos gengivais e ligamentares advindos da mesma passagem, nas mesmas condições experimentais e provenientes dos mesmos indivíduos, assim como um dos primeiros trabalhos que compararam fibroblastos do mesmo doador (SOMERMAN et al., 1988). De certa forma, por que não pensar que estas diferenças podem também existir entre essas duas populações celulares in vivo?

Vários fatores poderiam contribuir para os contrastes vistos no comportamento das células ligamentares em comparação com as células gengivais. Em primeiro lugar, fibroblastos ligamentares e gengivais podem estar continuamente em estágios de diferenciação distintos in vivo (GOULD, 1983), assim como in vitro. Em segundo lugar, a obtenção dos fibroblastos para serem estudados em cultura poderia ter selecionado populações celulares específicas e não similares de cada tipo de explant, sendo que ao decorrer das passagens essas diferenças entre eles poderiam aumentar ainda mais. Finalmente, fibroblastos gengivais e ligamentares podem ter cada um suas populações celulares únicas (SOMERMAN et al., 1988). Muito provavelmente, essas células cultivadas a partir de explants são populações heterogêneas (HASSELL; STANEK, 1983; MCCULLOCH, 1985; ROBERTS; MOREY, 1985) e isso sugere comportamentos diferenciais, indicativos de funções distintas na manutenção do periodonto. Além disso, alguns autores chegaram a sugerir que essas diferenças poderiam estar relacionadas ao número de divisões celulares entre esses dois tipos de células in vitro (VOGEL; KELLEY; STEWART, 1981). Essas dissimilaridades podem ser importantes ao considerar o desenvolvimento dessas células e a sua participação na resposta imune do indivíduo frente ao desafio microbiano característico da doença periodontal. 
No entanto, no atual estágio de conhecimento à respeito dessas diferenças observadas entre os dois tipos celulares, o que parece realmente ser esclarecedor é a expressão diferencial de receptores de superfície disponíveis para ligação e ainda diferentes mecanismos de sinalização intracelular que podem modular e decidir ou não se a célula expressa determinada citocina. A maior expressão de receptores do tipo TLR-4 em fibroblastos gengivais (GUTIERREZ-VENEGAS et al., 2006) e de TLR-2 em fibroblastos ligamentares (HATAKEYAMA et al., 2003) é uma das explicações plausíveis para tais diferenças na expressão e produção de citocinas. Podemos sugerir a participação efetiva dos fibroblastos gengivais e ligamentares na produção de citocinas e quimiocinas no contexto da resposta inflamatória de maneira distinta e relevante, já que essa não seria a sua função primordial como célula residente do tecido periodontal normal. 
<smiles>CCCC</smiles> 


\section{Conchusão}

\#

Nas condições de realização deste trabalho, pode-se concluir que fibroblastos humanos cultivados de ligamento periodontal e de gengiva produzem pró-colágeno tipo I e citocinas de maneira diferencial.

Conclui-se, em detalhes, que:

Fibroblastos provenientes de ligamento periodontal e tecido gengival humano expressam de RNAm para pró-colágeno tipo I, sendo que essa expressão é alterada pelo estímulo por LPS de $P$ gingivalis apenas nas células gengivais.

A produção da citocina IL-6 acontece de maneira diferencial nos fibroblastos gengivais e ligamentares, sendo mais intensa nos primeiros e ainda aumentada em ambos com o estímulo por LPS de $P$ gingivalis.

A concentração LPS de $P$ gingivalis parece induzir respostas diferenciais quanto à produção das quimiocinas MIP-1 $\alpha$ e SDF-1, pois os fibroblastos gengivais demonstraram uma maior produção de MIP-1 $\alpha$ com baixas concentrações de LPS ao longo do tempo. Já para o SDF-1 essa produção foi detectada em condição basal, mas diminuída com o aumento da concentração de LPS de P.gingivalis. Para os fibroblastos ligamentares, isso não ocorreu como um padrão, uma vez que a produção foi bem menor para estas duas quimiocinas. 
<smiles>CCCC</smiles> 


\section{RefêênciasB'b"iogáficas}

Abbas A, Lichtman A. Cytokines. In: Abbas A, Lichtman A, editors. Cellular and molecular immunology. 6th ed. Philadelphia: Saunders; 2007. p. 243-74.

Aiuti A, Webb IJ, Bleul C, Springer T, Gutierrez-Ramos JC. The chemokine SDF-1 is a chemoattractant for human CD34+ hematopoietic progenitor cells and provides a new mechanism to explain the mobilization of CD34+ progenitors to peripheral blood. J Exp Med. 1997 Jan 6;185(1):111-20.

Albandar JM, Rams TE. Global epidemiology of periodontal diseases: an overview. Periodontol 2000. 2002;29:7-10.

Almasri A, Wisithphrom K, Windsor LJ, Olson B. Nicotine and lipopolysaccharide affect cytokine expression from gingival fibroblasts. J Periodontol. 2007 Mar;78(3):533-41.

Ara T, Maeda Y, Fujinami Y, Imamura Y, Hattori T, Wang PL. Preventive effects of a Kampo medicine, Shosaikoto, on inflammatory responses in LPS-treated human gingival fibroblasts. Biol Pharm Bull. 2008 Jun;31(6):1141-4.

Bartel DP, Chen CZ. Micromanagers of gene expression: the potentially widespread influence of metazoan microRNAs. Nat Rev Genet. 2004 May;5(5):396-400.

Beertsen W, McCulloch CA, Sodek J. The periodontal ligament: a unique, multifunctional connective tissue. Periodontol 2000. 1997 Feb;13:20-40.

Berkovitz B, Shore R. Cells of the periodontal ligament. In: Berkovitz B, Moxham B, Newman H, editors. The periodontal ligament in health and disease. London: Pergamon; 1982.

Bleul CC, Fuhlbrigge RC, Casasnovas JM, Aiuti A, Springer TA. A highly efficacious lymphocyte chemoattractant, stromal cell-derived factor 1 (SDF-1). J Exp Med. 1996 Sep 1;184(3):1101-9. 
Bonecchi R, Polentarutti N, Luini W, Borsatti A, Bernasconi S, Locati M, et al. Upregulation of CCR1 and CCR3 and induction of chemotaxis to CC chemokines by IFNgamma in human neutrophils. J Immunol. 1999 Jan 1;162(1):474-9.

Brouty-Boye D, Pottin-Clemenceau C, Doucet C, Jasmin C, Azzarone B. Chemokines and CD40 expression in human fibroblasts. Eur J Immunol. 2000 Mar;30(3):914-9.

Chan JR, Hyduk SJ, Cybulsky MI. Chemoattractants induce a rapid and transient upregulation of monocyte alpha4 integrin affinity for vascular cell adhesion molecule 1 which mediates arrest: an early step in the process of emigration. J Exp Med. 2001 May 21;193(10):1149-58.

Chen D, Nie M, Fan MW, Bian Z. Anti-inflammatory activity of curcumin in macrophages stimulated by lipopolysaccharides from Porphyromonas gingivalis. Pharmacology. 2008;82(4):264-9.

Choi SJ, Cruz JC, Craig F, Chung H, Devlin RD, Roodman GD, et al. Macrophage inflammatory protein 1-alpha is a potential osteoclast stimulatory factor in multiple myeloma. Blood. 2000 Jul 15;96(2):671-5.

Cook DN. The role of MIP-1 alpha in inflammation and hematopoiesis. J Leukoc Biol. 1996 Jan;59(1):61-6.

Dieu MC, Vanbervliet B, Vicari A, Bridon JM, Oldham E, Ait-Yahia S, et al. Selective recruitment of immature and mature dendritic cells by distinct chemokines expressed in different anatomic sites. J Exp Med. 1998 Jul 20;188(2):373-86.

Ekhlassi S, Scruggs LY, Garza T, Montufar-Solis D, Moretti AJ, Klein JR. Porphyromonas gingivalis lipopolysaccharide induces tumor necrosis factor-alpha and interleukin-6 secretion, and CCL25 gene expression, in mouse primary gingival cell lines: interleukin-6-driven activation of CCL2. J Periodontal Res. 2008 Aug;43(4):431-9.

Fedyk ER, Jones D, Critchley HO, Phipps RP, Blieden TM, Springer TA. Expression of stromal-derived factor-1 is decreased by IL-1 and TNF and in dermal wound healing. $\mathrm{J}$ Immunol. 2001 May 1;166(9):5749-54. 
Fine DH, Markowitz K, Furgang D, Fairlie K, Ferrandiz J, Nasri C, et al. Macrophage Inflammatory Protein-1 alpha: A Salivary Biomarker of Bone Loss in a Longitudinal Cohort Study of Children at Risk for Agressive Periodontal Disease? J Periodontol. 2009;80(1):106-13.

Fiorellini J, Kim D, Ishikawa S. The Tooth-Suporting Structures. In: Carranza, editor. Carranza's Clinical Periodontology

10th ed. St. Louis:

; 2006. p. 68-92.

Garlet GP, Cardoso CR, Silva TA, Ferreira BR, Avila-Campos MJ, Cunha FQ, et al. Cytokine pattern determines the progression of experimental periodontal disease induced by Actinobacillus actinomycetemcomitans through the modulation of MMPs, RANKL, and their physiological inhibitors. Oral Microbiol Immunol. 2006 Feb;21(1):12-20.

Garlet GP, Martins W, Jr., Ferreira BR, Milanezi CM, Silva JS. Patterns of chemokines and chemokine receptors expression in different forms of human periodontal disease. $\mathrm{J}$ Periodontal Res. 2003 Apr;38(2):210-7.

Garlet GP, Martins W, Jr., Fonseca BA, Ferreira BR, Silva JS. Matrix metalloproteinases, their physiological inhibitors and osteoclast factors are differentially regulated by the cytokine profile in human periodontal disease. J Clin Periodontol. 2004 Aug;31(8):671-9.

Gemmell E, Marshall RI, Seymour GJ. Cytokines and prostaglandins in immune homeostasis and tissue destruction in periodontal disease. Periodontol 2000. 1997 Jun;14:112-43.

Genco RJ, Loe H. The role of systemic conditions and disorders in periodontal disease. Periodontol 2000. 1993 Jun;2:98-116.

Giannopoulou C, Cimasoni G. Functional characteristics of gingival and periodontal ligament fibroblasts. J Dent Res. 1996 Mar;75(3):895-902.

Gomes BP, Jacinto RC, Pinheiro ET, Sousa EL, Zaia AA, Ferraz CC, et al. Porphyromonas gingivalis, Porphyromonas endodontalis, Prevotella intermedia and Prevotella nigrescens in endodontic lesions detected by culture and by PCR. Oral Microbiol Immunol. 2005 Aug;20(4):211-5. 
Gould TR. Ultrastructural characteristics of progenitor cell populations in the periodontal ligament. J Dent Res. 1983 Aug;62(8):873-6.

Gutierrez-Venegas G, Kawasaki-Cardenas P, Cruz-Arroyo SR, Perez-Garzon M, Maldonado-Frias S. Actinobacillus actinomycetemcomitans lipopolysaccharide stimulates the phosphorylation of p44 and p42 MAP kinases through CD14 and TLR-4 receptor activation in human gingival fibroblasts. Life Sci. 2006 Apr 25;78(22):2577-83.

Gutierrez-Venegas G, Maldonado-Frias S, Ontiveros-Granados A, Kawasaki-Cardenas P. Role of p38 in nitric oxide synthase and cyclooxygenase expression, and nitric oxide and PGE2 synthesis in human gingival fibroblasts stimulated with lipopolysaccharides. Life Sci. 2005 May 20;77(1):60-73.

Han JH, Choi SJ, Kurihara N, Koide M, Oba Y, Roodman GD. Macrophage inflammatory protein-1alpha is an osteoclastogenic factor in myeloma that is independent of receptor activator of nuclear factor kappaB ligand. Blood. 2001 Jun 1;97(11):3349-53.

Hassell TM, Stanek EJ, 3rd. Evidence that healthy human gingiva contains functionally heterogeneous fibroblast subpopulations. Arch Oral Biol. 1983;28(7):617-25.

Hatakeyama J, Tamai R, Sugiyama A, Akashi S, Sugawara S, Takada H. Contrasting responses of human gingival and periodontal ligament fibroblasts to bacterial cell-surface components through the CD14/Toll-like receptor system. Oral Microbiol Immunol. 2003 Feb;18(1):14-23.

Havens AM, Chiu E, Taba M, Wang J, Shiozawa Y, Jung Y, et al. Stromal-derived factor-1alpha (CXCL12) levels increase in periodontal disease. J Periodontol. 2008 May;79(5):845-53.

Herlaar E, Brown Z. p38 MAPK signalling cascades in inflammatory disease. Mol Med Today. 1999 Oct;5(10):439-47.

Hosokawa Y, Hosokawa I, Ozaki K, Nakae H, Murakami K, Miyake Y, et al. CXCL12 and CXCR4 expression by human gingival fibroblasts in periodontal disease. Clin Exp Immunol. 2005 Sep;141(3):467-74. 
Jiang Y, Graves DT. Periodontal pathogens stimulate CC-chemokine production by mononuclear and bone-derived cells. J Periodontol. 1999 Dec;70(12):1472-8.

John AE, Lukacs NW. Chemokines and asthma. Sarcoidosis Vasc Diffuse Lung Dis. 2003 Oct;20(3):180-9.

Kabashima H, Yoneda M, Nagata K, Hirofuji T, Maeda K. The presence of chemokine (MCP-1, MIP-1alpha, MIP-1beta, IP-10, RANTES)-positive cells and chemokine receptor (CCR5, CXCR3)-positive cells in inflamed human gingival tissues. Cytokine. 2002 Oct $21 ; 20(2): 70-7$.

Kasama T, Strieter RM, Standiford TJ, Burdick MD, Kunkel SL. Expression and regulation of human neutrophil-derived macrophage inflammatory protein 1 alpha. J Exp Med. 1993 Jul 1;178(1):63-72.

Kent LW, Rahemtulla F, Michalek SM. Interleukin (IL)-1 and Porphyromonas gingivalis lipopolysaccharide stimulation of IL-6 production by fibroblasts derived from healthy or periodontally diseased human gingival tissue. J Periodontol. 1999 Mar;70(3):274-82.

Kim HK, Kim JE, Chung J, Han KS, Cho HI. Surface expression of neutrophil CXCR4 is down-modulated by bacterial endotoxin. Int J Hematol. 2007 Jun;85(5):390-6.

Kook SH, Hwang JM, Park JS, Kim EM, Heo JS, Jeon YM, et al. Mechanical force induces type I collagen expression in human periodontal ligament fibroblasts through activation of ERK/JNK and AP-1. J Cell Biochem. 2009 Feb 10.

Kuru L, Parkar MH, Griffiths GS, Newman HN, Olsen I. Flow cytometry analysis of gingival and periodontal ligament cells. J Dent Res. 1998 Apr;77(4):555-64.

Lenoir M, Djerdjouri B, Perianin A. Stroma cell-derived factor 1alpha mediates desensitization of human neutrophil respiratory burst in synovial fluid from rheumatoid arthritic patients. J Immunol. 2004 Jun 1;172(11):7136-43.

Letzelter C, Croute F, Pianezzi B, Roques C, Soleilhavoup JP. Supernatant cytotoxicity and proteolytic activity of selected oral bacteria against human gingival fibroblasts in vitro. Arch Oral Biol. 1998 Jan;43(1):15-23. 
Link DC. Neutrophil homeostasis: a new role for stromal cell-derived factor-1. Immunol Res. 2005;32(1-3):169-78.

Lodish HF, Zhou B, Liu G, Chen CZ. Micromanagement of the immune system by microRNAs. Nat Rev Immunol. 2008 Feb;8(2):120-30.

Lukacs NW. Role of chemokines in the pathogenesis of asthma. Nat Rev Immunol. 2001 Nov;1(2):108-16.

Luster AD. Chemokines--chemotactic cytokines that mediate inflammation. N Engl J Med. 1998 Feb 12;338(7):436-45.

Mahanonda R, Sa-Ard-Iam N, Montreekachon P, Pimkhaokham A, Yongvanichit K, Fukuda MM, et al. IL-8 and IDO expression by human gingival fibroblasts via TLRs. J Immunol. 2007 Jan 15;178(2):1151-7.

Mariotti A, Cochran DL. Characterization of fibroblasts derived from human periodontal ligament and gingiva. J Periodontol. 1990 Feb;61(2):103-11.

Martin C, Burdon PC, Bridger G, Gutierrez-Ramos JC, Williams TJ, Rankin SM. Chemokines acting via CXCR2 and CXCR4 control the release of neutrophils from the bone marrow and their return following senescence. Immunity. 2003 Oct;19(4):583-93.

Martinez EF, Araujo VC. In vitro immunoexpression of extracellular matrix proteins in dental pulpal and gingival human fibroblasts. Int Endod J. 2004 Nov;37(11):749-55.

Maurer M, von Stebut E. Macrophage inflammatory protein-1. Int J Biochem Cell Biol. 2004 Oct;36(10):1882-6.

Mayrand D, Holt SC. Biology of asaccharolytic black-pigmented Bacteroides species. Microbiol Rev. 1988 Mar;52(1):134-52.

McCulloch CA. Progenitor cell populations in the periodontal ligament of mice. Anat Rec. 1985 Mar;211(3):258-62. 
McCulloch CA, Lekic P, McKee MD. Role of physical forces in regulating the form and function of the periodontal ligament. Periodontol 2000. 2000 Oct;24:56-72.

Minami T, Kuroishi T, Ozawa A, Shimauchi H, Endo Y, Sugawara S. Histamine amplifies immune response of gingival fibroblasts. J Dent Res. 2007 Nov;86(11):1083-8.

Newman M, Takei H, Klokkevold P, Carranza F. Carranza's Clinical Periodontology. 10th ed. St. Louis: Saunders, Elsevier; 2006.

Offenbacher S, Barros SP, Beck JD. Rethinking periodontal inflammation. J Periodontol. 2008 Aug;79(8 Suppl):1577-84.

Offenbacher S, Barros SP, Singer RE, Moss K, Williams RC, Beck JD. Periodontal disease at the biofilm-gingival interface. J Periodontol. 2007 Oct;78(10):1911-25.

Ogura N, Tobe M, Sakamaki H, Nagura H, Abiko Y, Kondoh T. Tumor necrosis factoralpha increases chemokine gene expression and production in synovial fibroblasts from human temporomandibular joint. J Oral Pathol Med. 2005 Jul;34(6):357-63.

Okada N, Kobayashi M, Mugikura K, Okamatsu Y, Hanazawa S, Kitano S, et al. Interleukin-6 production in human fibroblasts derived from periodontal tissues is differentially regulated by cytokines and a glucocorticoid. J Periodontal Res. 1997 Oct;32(7):559-69.

Oliveira TM, Sakai VT, Machado MA, Dionisio TJ, Cestari TM, Taga R, et al. COX-2 inhibition decreases VEGF expression and alveolar bone loss during the progression of experimental periodontitis in rats. J Periodontol. 2008 Jun;79(6):1062-9.

Palmqvist P, Lundberg P, Lundgren I, Hanstrom L, Lerner UH. IL-1beta and TNF-alpha regulate IL-6-type cytokines in gingival fibroblasts. J Dent Res. 2008 Jun;87(6):558-63.

Patil C, Rossa C, Jr., Kirkwood KL. Actinobacillus actinomycetemcomitans lipopolysaccharide induces interleukin-6 expression through multiple mitogen-activated protein kinase pathways in periodontal ligament fibroblasts. Oral Microbiol Immunol. 2006 Dec;21(6):392-8. 
Quirynen M, Teughels W, Haake S, M. N. Microbiology of periodontal diseases. In: Carranza, editor. Carranza's Clinical Periodontology. 10th ed. St. Louis: Elsevier; 2006. p. 134-69.

Ravanti L, Hakkinen L, Larjava H, Saarialho-Kere U, Foschi M, Han J, et al. Transforming growth factor-beta induces collagenase-3 expression by human gingival fibroblasts via p38 mitogen-activated protein kinase. J Biol Chem. 1999 Dec 24;274(52):37292-300.

Reeve CM, Wentz FM. The prevalence, morphology, and distribution of epithelial rests in the human periodontal ligament. Oral Surg Oral Med Oral Pathol. 1962 Jul;15:785-93.

Rietschel ET, Brade H, Holst O, Brade L, Muller-Loennies S, Mamat U, et al. Bacterial endotoxin: Chemical constitution, biological recognition, host response, and immunological detoxification. Curr Top Microbiol Immunol. 1996;216:39-81.

Roberts WE, Morey ER. Proliferation and differentiation sequence of osteoblast histogenesis under physiological conditions in rat periodontal ligament. Am J Anat. 1985 Oct;174(2):105-18.

Rodini CO, Batista AC, Dionisio TJ, Santos CF, Cunha FQ, Lara VS. Morphologic evaluation and expression of matrix metalloproteinases- 2 and 9 and nitric oxide during experimental periodontal disease in rat. J Mol Histol. 2008 Jun;39(3):275-82.

Romanos GE, Bernimoulin JP. [Collagen as a basic element of the periodontium: immunohistochemical aspects in the human and animal. 1. Gingiva and alveolar bone]. Parodontol. 1990 Nov;1(4):363-75.

Roodman GD. Regulation of osteoclast differentiation. Ann N Y Acad Sci. 2006 Apr;1068:100-9.

Ryu OH, Choi SJ, Firatli E, Choi SW, Hart PS, Shen RF, et al. Proteolysis of macrophage inflammatory protein-1alpha isoforms LD78beta and LD78alpha by neutrophil-derived serine proteases. J Biol Chem. 2005 Apr 29;280(17):17415-21. 
Ryu OH, Choi SJ, Linares AM, Song IS, Kim YJ, Jang KT, et al. Gingival epithelial cell expression of macrophage inflammatory protein-1alpha induced by interleukin-1beta and lipopolysaccharide. J Periodontol. 2007 Aug;78(8):1627-34.

Santos CF, Akashi AE, Dionisio TJ, Sipert CR, Didier DN, Greene AS, et al. Characterization of a local Renin-Angiotensin system in rat gingival tissue. J Periodontol. 2009 Jan;80(1):130-9.

Schall TJ, Bacon K, Camp RD, Kaspari JW, Goeddel DV. Human macrophage inflammatory protein alpha (MIP-1 alpha) and MIP-1 beta chemokines attract distinct populations of lymphocytes. J Exp Med. 1993 Jun 1;177(6):1821-6.

Sipert CR. Produção de MIP-1 alpha e SDF-1 por fibroblastos de polpa dental humana em cultura frente ao desafio com Enterococcus faecalis inativado por calor [Dissertação]. Bauru: Universidade de São Paulo; 2007.

Slots J, Rams TE. New views on periodontal microbiota in special patient categories. J Clin Periodontol. 1991 Jul;18(6):411-20.

Socransky SS, Haffajee AD. The bacterial etiology of destructive periodontal disease: current concepts. J Periodontol. 1992 Apr;63(4 Suppl):322-31.

Somerman MJ, Archer SY, Imm GR, Foster RA. A comparative study of human periodontal ligament cells and gingival fibroblasts in vitro. J Dent Res. 1988 Jan;67(1):66-70.

Sugawara S, Sugiyama A, Nemoto E, Rikiishi H, Takada H. Heterogeneous expression and release of CD14 by human gingival fibroblasts: characterization and CD14-mediated interleukin-8 secretion in response to lipopolysaccharide. Infect Immun. 1998 Jul;66(7):3043-9.

Sugiyama A, Ogawa T, Daikuhara Y, Takada H. Enhancement of hepatocyte growth factor (scatter factor) production by human gingival fibroblasts in culture stimulated with Porphyromonas gingivalis fimbriae. J Med Microbiol 2000;49(4):319-25.

Sun Y, Shu R, Zhang MZ, Wu AP. Toll-like receptor 4 signaling plays a role in triggering periodontal infection. FEMS Immunol Med Microbiol. 2008 Apr;52(3):362-9. 
Tabeta K, Yamazaki K, Akashi S, Miyake K, Kumada H, Umemoto T, et al. Toll-like receptors confer responsiveness to lipopolysaccharide from Porphyromonas gingivalis in human gingival fibroblasts. Infect Immun. 2000 Jun;68(6):3731-5.

Takashiba S, Naruishi K, Murayama Y. Perspective of cytokine regulation for periodontal treatment: fibroblast biology. J Periodontol. 2003 Jan;74(1):103-10.

Takashiba S, Takigawa M, Takahashi K, Myokai F, Nishimura F, Chihara T, et al. Interleukin-8 is a major neutrophil chemotactic factor derived from cultured human gingival fibroblasts stimulated with interleukin-1 beta or tumor necrosis factor alpha. Infect Immun. 1992 Dec;60(12):5253-8.

Tamura M, Tokuda M, Nagaoka S, Takada H. Lipopolysaccharides of Bacteroides intermedius (Prevotella intermedia) and Bacteroides (Porphyromonas) gingivalis induce interleukin-8 gene expression in human gingival fibroblast cultures. Infect Immun. 1992 Nov;60(11):4932-7.

Telles PD, Hanks CT, Machado MA, Nor JE. Lipoteichoic acid up-regulates VEGF expression in macrophages and pulp cells. J Dent Res. 2003 Jun;82(6):466-70.

Ten Cate A, Deporter D. The degradative role of the fibroblast in the remodeling and turnover of collagen in soft connective tissue. Anat Rec 1975;182(1):1-13.

Uehara A, Takada H. Functional TLRs and NODs in human gingival fibroblasts. J Dent Res. 2007 Mar;86(3):249-54.

van Winkelhoff AJ, van Steenbergen TJ, de Graaff J. The role of black-pigmented Bacteroides in human oral infections. J Clin Periodontol. 1988 Mar;15(3):145-55.

Verardi S, Page RC, Ammons WF, Bordin S. Differential chemokine response of fibroblast subtypes to complement C1q. J Periodontal Res. 2007 Feb;42(1):62-8.

Vogel KG, Kelley RO, Stewart C. Loss of organized fibronectin matrix from the surface of aging diploid fibroblasts (IMR-90). Mech Ageing Dev. 1981;16(4):295-302. 
Wang PL, Azuma Y, Shinohara M, Ohura K. Toll-like receptor 4-mediated signal pathway induced by Porphyromonas gingivalis lipopolysaccharide in human gingival fibroblasts. Biochem Biophys Res Commun. 2000 Jul 14;273(3):1161-7.

Wang PL, Sato K, Oido M, Fujii T, Kowashi Y, Shinohara M, et al. Involvement of CD14 on human gingival fibroblasts in Porphyromonas gingivalis lipopolysaccharidemediated interleukin-6 secretion. Arch Oral Biol. 1998 Sep;43(9):687-94.

Wang PL, Shirasu S, Shinohar M, Azuma Y, Daito M, Yasuda H, et al. IL-10 inhibits Porphyromonas gingivalis LPS-stimulated human gingival fibroblasts production of IL-6. Biochem Biophys Res Commun. 1999 Sep 24;263(2):372-7.

Yamaji Y, Kubota T, Sasaguri K, Sato S, Suzuki Y, Kumada H, et al. Inflammatory cytokine gene expression in human periodontal ligament fibroblasts stimulated with bacterial lipopolysaccharides. Infect Immun. 1995 Sep;63(9):3576-81.

Yamamoto T, Kita M, Oseko F, Nakamura T, Imanishi J, Kanamura N. Cytokine production in human periodontal ligament cells stimulated with Porphyromonas gingivalis. J Periodontal Res. 2006 Dec;41(6):554-9.

Yamamoto T, Wakita M. Bundle formation of principal fibers in rat molars. J Periodontal Res 1982;27(20).

Yamasaki M, Nakata K, Imaizumi I, Iwama A, Nakane A, Nakamura H. Cytotoxic effect of endodontic bacteria on periapical fibroblasts. J Endod. 1998 Aug;24(8):534-9.

Yang SK, Eckmann L, Panja A, Kagnoff MF. Differential and regulated expression of CX-C, C-C, and C-chemokines by human colon epithelial cells. Gastroenterology. 1997 Oct;113(4):1214-23.

Zhang D, Chen L, Shenglai L, Zhiyuan G, Yan J. Lipopolysaccharide (LPS) of Porphyromonas gingivalis induces IL-1beta, TNF-alpha and IL-6 production by THP-1 cells in a way different from that of Escherichia coli LPS. Innate Immun 2008;14(2):99107. 
Zlotnik A, Yoshie O. Chemokines: a new classification system and their role in immunity. Immunity. $2000 \mathrm{Feb}$;2(2):121-7. 